Universidade de Brasília

Faculdade de Tecnologia

Departamento de Engenharia Elétrica

Estágio Supervisionado 2

\title{
Proposta de Arquitetura de Gerência para a RedUnB usando a \\ Plataforma Tivoli TME 10
}

\author{
Autores: \\ Alvaro Magalhães Neto - 93/04495 \\ Trajano Passos Ferraz Moreira - 94/13481 \\ Orientadores: \\ Ricardo Staciarini Puttini \\ Rafael Timóteo de Sousa Júnior
}

$1^{\circ}$ Semestre - 2000 


\section{Agradecimentos:}

Agradeço aos meus pais por sempre me darem apoio incondicional em todas as horas, pelo incentivo e pelo amor dedicado a mim e a meus irmãos. Agradeço aos amigos que compartilharam comigo as alegrias e sofrimentos durante estes anos na Universidade; e agradeço a Deus, por tudo.

\section{Alvaro}

Agradeço a Deus pela vida, a meus pais pela força e amor, a meus irmãos pela amizade, a meus sobrinhos pela alegria.

Trajano 


\section{Proposta de Arquitetura de Gerência para a RedUnB usando a Plataforma Tivoli TME 10}

\section{Resumo:}

Neste projeto são estudados os componentes da arquitetura de gerência SNMP e é concebida e implementada uma estação de gerência para a Rede de Alta Velocidade da UnB (RedUnB) baseada na ferramenta Tivoli TME 10 e em agentes SNMP, RMOM e RMOM-2, MIB e MIB-II distribuídos pelos elementos da rede (switches, hubs, routers e hosts).

Inicialmente são apresentadas as teorias envolvidas para a realização deste projeto; é apresentado também o software Tivoli TME 10, assim como suas características e em que ele será útil ao projeto, em especial são tratados o Tivoli TME 10 Framework sobre o qual rodam os módulos, Tivoli NetView e Tivoli Remote Control.

Em seguida é apresentada uma proposta de gerência para a RedUnB tendo como base o software utilizado e as experiências realizadas durante o transcurso deste projeto.

Como o Backbone do Laboratório de Redes se assemelha ao Backbone da RedUnB, em uma escala menor, foi possível ter uma idéia bastante clara das necessidades de uma rede com o porte e a diversidade de ambientes existentes como o da RedUnB.

Finalmente são sugeridos alguns pacotes de gerência do Tivoli, cada um com várias disciplinas que realizam diferentes funções e que seriam de grande utilidade para que a gerência da RedUnB possa ser realizada de maneira eficiente. 
Proposta de Arquitetura de Gerência para a RedUnB usando a Plataforma Tivoli TME 10

\section{Índice:}

$\begin{array}{ll}\text { Resumo } & 2\end{array}$

$\begin{array}{ll}\text { Índice de Figuras } & 7\end{array}$

$\begin{array}{lr}\text { Índice de Tabelas } & 8\end{array}$

Lista de Acrônimos 9

1 - Introdução 10

2 - Definições e Conceitos 12

2.1 - Conceito de gerência de redes 12

2.1.1 - Agentes 12

2.1.2-Gerentes 12

2.1.3-MIB 13

2.1.4 - Polling e Comunicação de Eventos 13

2.1.5 - Objeto Gerenciado 13

2.1.6 - Monitores Remotos 13

2.2 - Modelos de Gerenciamento 14

2.2.1 - Modelo Internet 14

2.2.2 - Modelo OSI 14

2.3 - Protocolos e Padrões de Gerenciamento 17

$\begin{array}{ll}2.3 .1 \text { - Proxies } & 17\end{array}$

2.3.2-CMIP 18

2.4 - Comparação: SNMP versus CMIP 18

3 - Conceitos de Protocolos Utilizados 20

3.1 - Gerência de Redes TCP/IP 20

3.1.1 - Arquitetura de Gerenciamento 21 
3.2 - Simple Network Management Protocol (SNMP) 22

3.2.1 - O Protocolo SNMP 22

3.2.2 - Simple Network Management Protocol - SNMPv2 24

3.2.3 - Simple Network Management Protocol - SNMPv3 26

3.3 - Estrutura e Identificadores das Informações Gerenciais 26

3.3.1 - Tipos de Dados 27

3.3.1.1 - Tipos Universais 27

3.3.1.2 - Tipos de Aplicação 27

3.4 - Identificadores de Objetos 28

3.5 - Estrutura da MIB $\quad 28$

3.6 - Base de Informações Gerenciais 29

3.7 - Remote Network Monitoring MIB (RMON) 29

$\begin{array}{ll}3.7 .1-\mathrm{RMON} 1 & 30\end{array}$

3.7.2 - RMON2 31

3.7.3 - Controle de Monitoramento Remoto 32

3.7.4 - Múltiplos Gerentes 32

3.7.5 - Gerenciamento de Tabelas 33

3.8 - MIB 33

3.8.1 - Objeto gerenciado 33

3.8.2 - O Grupo SYSTEM 36

3.8.3 - O Grupo Interfaces 37

3.8.4 - O Grupo Address Translation 41

3.8.5 - O Grupo IP 41

3.8.6 - O Grupo ICMP 46

3.8.7 - O Grupo TCP 48

3.8.8 - O Grupo UDP 51

3.8.9 - O Grupo EGP 53

3.8.10 - O Grupo CMOT 56

3.8.11 - O Grupo Transmission 56 
3.8.12 - O Grupo SNMP 56

3.9 - Comparação entre a MIB da OSI e a MIB da Internet 60

3.10 - Remote Procedure Call - RPC 60

3.10.1 - Modelo Cliente / Servidor 61

3.10.2 - Mecanismo 61

3.10.3 - Funcionamento do RPC 61

3.10.3.1 - Argumentos do procedimento $\quad 61$

3.10.3.2 - Comunicação $\quad 61$

3.10.3.3 - Transporte $\quad 62$

3.10.3.4 - Timeout $\quad 62$

3.10.4 - Identificando Serviços RPC 62

3.10.4.1 - RPC Portmapper 63

3.10.4.2 - Números de versão RPC 63

4 - Software Tivoli

4.1 - Tivoli Management Environment 10 (TME 10) 64

4.1.1 - Tivoli TME 10 Estrutura do Produto 64

4.1.2 - Tivoli Management Environment 10 Framework 65

4.1.2.1 - Componentes do TME 10 Framework 67

4.2 - O Gateway e o Cliente Endpoint 68

4.3 - Disciplinas do Tivoli $\quad 70$

4.3.1 - Disciplinas de Monitoramento da Rede $\quad 70$

4.3.2 - Disciplinas de Segurança $\quad 70$

4.3.3 - Disciplina de Inventário $\quad 70$

4.3.4 - Disciplina de Distribuição de Software 71

4.3.5 - Disciplina de Servidores e Clientes 71

4.3.6 - Disciplina de Help Desk 71

4.3.7 - Disciplina de Internet $\quad 72$ 
Proposta de Arquitetura de Gerência para a RedUnB usando a Plataforma Tivoli TME 10

4.4 - Definições Específicas $\quad 72$

4.3.1 - TME 10 desktop $\quad 72$

4.3.2 - Remote Control 72

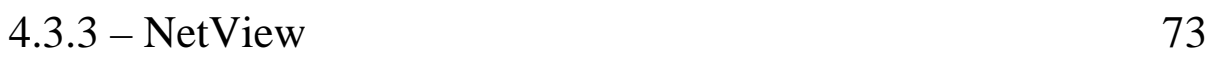

4.3.4 - Distributed Monitoring 74

4.3.5 - Software Distribuiton 75

5 - Metodologia, Resultados e Análise 76

5.1 - TME 10 Framework $\quad 76$

$\begin{array}{ll}5.2 \text { - NetView } & 77\end{array}$

5.3 - Remote Control $\quad 81$

5.3.1 - Resolução de Problemas do Remote Control 86

$5.4-$ Sniffer $\quad 86$

6 - Proposta de gerência $\quad 88$

6.2 - Sugestões de Pacotes do Tivoli TME 10 a Serem Adquiridos 90

7 - Conclusões

$\begin{array}{ll}\text { Bibliografia } & 93\end{array}$ 
Proposta de Arquitetura de Gerência para a RedUnB usando a Plataforma Tivoli TME 10

\section{Índice de Figuras:}

Figura 3.1- Diferença entre RMON e RMON2 31

Figura 3.2 - Árvore MIB II

Figura 4.1- Estrutura do Tivoli TME

Figura 4.2 - Relação dos produtos da linha TME 10 entre si de forma

$\begin{array}{ll}\text { hierárquica } & 68\end{array}$

Figura 4.3 - Gateway e o Cliente Endpoint 69

Figura 5.1 - Interface gráfica do Software Tivoli 76

Figura 5.2 - Mapeamento da RedUnB e rede ENE pelo software NetView 78

Figura 5.3 - Visualização com sniffer da utilização do protocolo SNMP pelo

$\begin{array}{ll}\text { Netview } & 81\end{array}$

Figura 5.4 - Policy Region: RedUnB $\quad 82$

$\begin{array}{lr}\text { Figura } 5.5 \text { - Remote Control } & 83\end{array}$

Figura 5.6 - Remote Control Options $\quad 83$

Figura 5.7 - Remote Control action options $\quad 84$

Figura 5.8 - Remote Control time options $\quad 84$

Figura 5.9 - Descoberta de qual protocolo é usado na aplicação Remote

Control 85

$\begin{array}{lr}\text { Figura 6.1- Proposta de Gerência } & 88\end{array}$ 


\section{Índice de Tabelas:}

Tabela 3.1 - Grupos de objetos usados pela MIB II 35

Tabela 3.2 - Objetos para Gerenciamento de Configuração (System) 36

Tabela 3.3 - Objetos para Gerenciamento de Falhas (System) 36

Tabela 3.4 - Objetos para Gerenciamento de Falhas (Interfaces) 37

Tabela 3.5 - Objetos para Gerência de Configuração (Interfaces) 38

Tabela 3.6 - Objetos para Gerência de Performance (Interfaces) 39

Tabela 3.7 - Objetos para Gerência de Contabilização (Interfaces) 40

Tabela 3.8 - Objetos para Gerenciamento de Falhas (Translation) 41

Tabela 3.9 - Objetos para Gerenciamento de Configuração (Translation) 43

Tabela 3.10 - Objetos para Gerenciamento de Performance (Translation) 44

Tabela 3.11 - Objetos para Gerenciamento de Contabilização (Translation) 46

Tabela 3.12 - Objetos do Grupo ICMP $\quad 47$

Tabela 3.13 - Objetos para Gerenciamento de Configuração (TCP) 48

Tabela 3.14 - Objetos para Gerenciamento de Performance (TCP) 49

Tabela 3.15 - Objetos para Gerenciamento de Contabilização (TCP) 50

Tabela 3.16 - Objetos para Gerenciamento de Performance (UDP) 51

Tabela 3.17 - Objetos para Gerenciamento de Contabilização (UDP) 52

Tabela 3.18 - Objetos para Gerenciamento de Falhas (EGP) 53

Tabela 3.19 - Objetos para Gerenciamento de Configuração (EGP) 54

Tabela 3.20 - Objetos para Gerenciamento de Performance (EGP) 55

Tabela 3.21 - Objetos para Gerenciamento de Falhas (SNMP) 57

Tabela 3.22 - Objetos para Gerenciamento de Performance (SNMP) 58

Tabela 3.23 - Objetos para Gerenciamento de Contabilização (SNMP) 59

Tabela 3.24 - Objetos para Gerenciamento de Segurança (SNMP) 59

Tabela 3.25 - Objetos para Gerenciamento de Configuração (SNMP) 60 
Lista de Acrônimos:

- AMO Asset Management Option

- CLI Command Line Interface

- GUI Graphical User Interface

- IP Internet Protocol

- ISO International Organization for Standardization

- LAN Local Area Network

- MIB Management Information Base

- OSI Open Systems Interconnection

- PDU Protocol Data Unit

- RCO Remote Control Option

- RFC Request for Comment

- RMO Remote Monitoring Option

- RMON Remote Network Monitoring

- RPC Remote Procedure Call

- SGMP Simple Gateway Monitoring Protocol

- SNMP Simple Network Management Protocol

- TCP Transmision Control Protocol

- TME Tivoli Management Environment

- TMR-S Tivoli Management Regions - Server

- UDP User Datagram Protocol

- WAN Wide Area Network 


\section{Proposta de Arquitetura de Gerência para a RedUnB usando a Plataforma Tivoli TME 10}

\section{1 - Introdução}

A necessidade de gerência das redes de comunicação torna-se cada vez mais evidente, devido ao volume e à complexidade das informações que trafegam, agregados à constante expansão e utilização das redes, ao compartilhamento de dispositivos e à utilização de aplicações distribuídas.

Este trabalho tem por objetivo desenvolver um sistema de gerência descentralizado, primeiramente no âmbito do Laboratório de Redes da UnB para futuramente ser expandido à RedUnB, tendo em vista as necessidades da mesma. As principais motivações para a realização deste projeto são a necessidade de implementação de um ambiente de rede confiável, proporcionando um nível maior de segurança dos dados que trafegam pela rede, a diversidade física da rede, diversidade de sistemas operacionais existentes em tal ambiente, a necessidade de controle de acesso à rede e controle de tráfego de pacotes, visando tornar a rede mais eficiente, evitando gargalos.

Este trabalho dá uma visão geral em gerência de redes, e para isso são apresentados conceitos de gerência e noções dos vários protocolos utilizados para a sua implementação.

Além disso, também será apresentado o software de gerência TIVOLI em especial os módulos NetView e Tivoli Framework que são utilizados na parte prática deste trabalho.

Primeiramente serão apresentados alguns conceitos básicos sobre gerência de redes onde serão incluídas as modalidades de gerência, tais como gerência de falhas, gerência de configuração, gerência de segurança, gerência de contabilização e gerência de performance.

Mais especificamente são tratadas as disciplinas de gerência pertinentes ao Tivoli que são utilizadas nos experimentos constantes neste relatório, são elas: disciplina de monitoramento (Distributed Monitoring), disciplina de distribuição de software (Software Distribution) e disciplina de controle remoto (Remote Control).

Serão detalhados os agentes SNMP e RMON que são fundamentais para a realização dos experimentos realizados. 


\section{Proposta de Arquitetura de Gerência para a RedUnB usando a Plataforma Tivoli TME 10}

Neste relatório são mostrados também os experimentos que foram implementados com a utilização do software Tivoli e suas disciplinas.

No Capítulo 2 tem-se as definições e conceitos gerais necessários a um melhor entendimento do trabalho.

No Capítulo 3 são colocados conceitos dos protocolos utilizados (SNMP (v.1, v.2, v.3), MIB e MIB-II, RMON e RMON2), também é colocado um conceito de gerência sobre TCP/IP e em especial é apresentado como cada um dos grupos de gerência (Gerência de configuração, Gerência de desempenho, Gerência de falhas, Gerência de contabilidade e Gerência de segurança) utiliza a MIB-II para realizar suas tarefas.

No Capítulo 4 é mostrado o software Tivoli e suas disciplinas.

No Capítulo 5 são tratados a metodologia utilizada para a realização deste projeto, os resultados obtidos experimentalmente pelo grupo e as análises destes resultados.

No Capítulo 6 apresentamos a proposta de gerência da RedUnB, que é a base desse projeto, tal proposta é fundamentada nos estudos realizados durante a verificação deste projeto. 


\section{Proposta de Arquitetura de Gerência para a RedUnB usando a Plataforma Tivoli TME 10}

\section{2 - Definições e Conceitos:}

\section{1 - Conceito de gerência de redes}

Pode-se dizer que a gerência de redes consiste no controle e administração de forma racional dos recursos de hardware e software em um ambiente distribuído, buscando melhor performance e eficiência do sistema, assim como um controle de uma rede de computadores e seus serviços.

Essa é uma definição genérica, independente de padronizações usado para descrever o gerenciamento de redes em sistemas distribuídos.

O gerenciamento de redes provê mecanismos para monitoração, controle e coordenação de recursos em um ambiente OSI e define padrões de protocolos OSI para a troca de informações entre estes recursos. Tem por objetivo maximizar o controle organizacional das redes de computadores, de maneira eficiente e confiável, ou seja, planejar, supervisionar, monitorar e controlar qualquer atividade da rede. Algumas funções do gerenciamento de redes são apresentadas e detalhadas mais à frente neste relatório.

Existem também alguns níveis de gerência que podem ser implementados dependendo do que se deseja, por exemplo, Objetos gerenciados, Sistemas de gerência de elementos, Gerenciador de elementos, Interface como usuário.

\subsection{1 - Agentes}

Os agentes são entidades que fazem a interface com os dispositivos a serem gerenciados. Eles incluem sistemas finais que suportam aplicações de usuários bem como os nós que oferecem um serviço de comunicação, tais como processadores de front-end, controladores de clusters, bridges e roteadores.

\subsection{2 - Gerentes}

Os gerentes são agentes que possuem uma NMA (network-managment application). O NMA pode ser entendido como uma aplicação que inclui uma interface de operador para permitir a um usuário autorizado gerenciar a rede. Usa-se o termo gerente para o software que monitora e controla a rede ou estação. 


\section{Proposta de Arquitetura de Gerência para a RedUnB usando a Plataforma Tivoli TME 10}

\subsection{3 - MIB}

A base de informação gerencial (MIB - Management Information Base) é o nome conceitual para a informação de gerenciamento, incluindo os objetos gerenciados e seus atributos, operações e notificações. Pode-se também considerar as informações para a configuração do sistema como também pertencentes à MIB.

\subsection{4 - Polling e Comunicação de Eventos}

A informação que é útil para o monitoramento da rede é coletada e armazenada pelos agentes, e disponibilizada para um ou muitos sistemas de gerenciamento. Duas técnicas são usadas para disponibilizar a informação do agente, que servirá para o gerenciamento: polling e comunicação de eventos. Polling é uma interação de solicitações/respostas entre gerente e agente. $\mathrm{O}$ gerente pode questionar qualquer agente (para o qual ele tem autorização) e requisitar os valores de vários elementos de informação; os agentes respondem com informações de sua MIB.

\subsection{5 - Objeto Gerenciado}

Um objeto gerenciado representa um recurso sujeito ao gerenciamento, isto é, que pode ser gerenciado. Ele é definido em termos de seus atributos, das operações a que pode ser submetido, das notificações que pode emitir e de seus relacionamentos com outros objetos gerenciados. O conjunto de objetos gerenciados, juntamente com seus atributos, operações e notificações, constituem a MIB.

\subsection{6 - Monitores Remotos}

Monitores remotos são utilizados para a execução continua de diagnósticos e manutenção de arquivos de log em relação ao desempenho da rede, através da inspeção dos objetos gerenciáveis da base de informações gerenciais e conseqüente composição de estatísticas sobre os dados coletados. A monitoração remota ajuda, ainda, a minimizar o tráfego de gerenciamento, colaborando com a atividade de gerência à medida que não gera sobrecarga ao sistema. 


\section{Proposta de Arquitetura de Gerência para a RedUnB usando a Plataforma Tivoli TME 10}

\section{2 - Modelos de Gerenciamento}

Os modelos de gerenciamento diferenciam-se nos aspectos organizacionais no que se refere à disposição dos gerentes na rede, bem como no grau da distribuição das funções de gerência. Na prática existem dois modelos adotados para gerência de redes: o Modelo Internet e o Modelo OSI.

\subsection{1 - Modelo Internet}

O modelo de gerenciamento Internet adota uma abordagem gerente/agente onde os agentes mantêm informações sobre recursos e os gerentes requisitam essas informações aos agentes.

O padrão Internet SMI (Structure of Management Information) especifica uma metodologia para definição da informação de gerenciamento contida na MIB. O SMI usa um subconjunto de tipos de dados ASN.1. A MIB define os elementos de gerenciamento de informação como variáveis e tabelas de variáveis.

\subsection{2 - Modelo OSI}

O gerenciamento no modelo OSI - Open Systems Interconnectíons da ISO International Organization for Standardízation baseia-se na teoria da orientação a objetos. Com isso, o sistema representa os recursos gerenciados através de entidades lógicas, as quais recebem a denominação de objetos gerenciados.

O modelo de gerência OSI permite a delegação das funções de monitoração aos agentes. Contudo, as funções de controle ainda ficam relegadas ao gerente, pois o conhecimento relativo à tomada de decisões gerenciais não se adapta para ser codificado em classes de objeto, ao contrário do conhecimento referente à monitoração, que é mais simples, geralmente estático e periódico.

Existem cinco áreas funcionais no gerenciamento num ambiente OSI: 


\section{Proposta de Arquitetura de Gerência para a RedUnB usando a Plataforma Tivoli TME 10}

\section{- Gerência de configuração}

A gerência de configuração (estado da rede) é composta, basicamente, pelas ferramentas que exercem controle, identificam, coletam dados, e provêem dados a objetos gerenciados, com o propósito de auxiliar a contínua operação dos serviços de comunicação.

Cabe ao gerenciamento de configuração (ou de nomes) informar quando houver um evento, e prover condições para que as pessoas dependentes daqueles recursos tenham informações suficientes para que os re-configurem com segurança.

\section{- Gerência de desempenho}

O objetivo da gerência de desempenho (performance ou vazão e taxa de erros) é ter uma gama de facilidades que permitam avaliar o comportamento de objetos gerenciados, bem como a efetividade e eficiência das atividades de interconexões.

As informações obtidas através das estatísticas de desempenho são de suma importância para os gerentes de rede, pois é através delas que se pode planejar, gerenciar e manter médias e grandes redes. Podendo-se, por exemplo, identificar com antecedência potenciais gargalos na rede e tomar ações preventivas para diminuir as chances de uma interrupção parcial ou total do serviço.

\section{- Gerência de falhas}

Pode-se definir o gerenciamento de falhas (comportamento anormal) como sendo o conjunto de facilidades que permitem a detecção, isolamento e correção de situações anormais em um ambiente de rede.

Devemos desatacar a diferença entre falha e erro; enquanto erro é apenas um evento, falhas são condições que requerem monitoramento e/ou ação por parte da gerência, a fim de sanar o problema.

Quando se dá uma falha, é necessário que, no menor período de tempo possível, sejam tomadas as seguintes atitudes: 


\section{Proposta de Arquitetura de Gerência para a RedUnB usando a Plataforma Tivoli TME 10}

Determinar exatamente onde a falha ocorreu;

Isolar a falha do restante da rede de forma que esta possa operar sem interferências;

Re-configurar ou modificar a rede, de forma a minimizar o impacto de operação do conjunto sem o componente em falha; e

Reparar ou trocar o componente defeituoso para que a rede volte a seu estado normal de operação.

\section{- Gerência de contabilidade}

A gerência de contabilidade (contabilização ou consumo de recursos) é constituída por ferramentas que permitem o estabelecimento de taxas para o uso de objetos gerenciados; assim como auxiliam a identificação de custos de uso dos mesmos.

Como razões para se efetivar tal acompanhamento pode-se incluir:

Usuários podem estar abusando de seus privilégios de acesso e, portanto, sobrecarregando a rede prejudicando o trabalho de outros;

Usuários podem estar utilizando a rede de forma ineficiente, assim o gerente desta pode auxiliar indicando formas e procedimentos para melhorar a performance e

O gerente de rede estará em melhor posição para planejar crescimentos na rede, se as informações de uso desta proverem detalhamento suficiente.

\section{- Gerência de segurança}

Características relacionadas com os aspectos de segurança de rede, essenciais para seu correto funcionamento e proteção dos objetos gerenciados. Aqui estão inclusos não só os aspectos de acesso a arquivos, mas também de políticas de senhas, monitoração de setores críticos e auditoria de registros $(\log s)$.

Em gerência de segurança (acesso) a manutenção de registros $(\log s)$ compõe uma importante ferramenta de trabalho. Pois estes são coleções de dados tomados ao longo de um intervalo de tempo, permitindo a análise de falhas e prevenção de incidentes. 


\section{Proposta de Arquitetura de Gerência para a RedUnB usando a Plataforma Tivoli TME 10}

Um dos aspectos a serem considerados no gerenciamento OSI é o fato de que tal modelo gera agentes mais complexos de serem desenvolvidos, consumindo mais recursos dos elementos de rede, enquanto economiza o uso da rede, devido a minimização dos pedidos de informações (pollings) necessários para obter dados sobre objetos gerenciados, livrando o gerente para tarefas mais inteligentes.

\section{3 - Protocolos e Padrões de Gerenciamento}

Os protocolos de gerenciamento de rede têm sido tradicionalmente implementados como protocolos do nível de aplicação. E até recentemente, cada vendedor costumava ter um método proprietário pelo qual seus agentes podiam se comunicar, o que levava a existência de incompatibilidades entre os diversos padrões.

A necessidade de uma representação padronizada foi sentida tanto pelo IAB (Internet Activities Board) quanto pela ISO. Enquanto a ISO trabalhou lentamente na especificação do seu padrão, o IAB saiu na frente com a proposta do SNMP em 1989, como uma solução temporária para gerenciamento de redes TCP/IP. A ISO só lançou seu padrão, chamado CMIP (Common Management Information Protocol), muito tempo depois. Devido à sua aceitação, o SNMP tornou-se um padrão de "facto" na indústria. Como consequiência desse sucesso, o SNMPv2 (SNMP versão 2) foi proposto em 1993. Em 1996, foi proposto o SNMPv3 recentemente aprovado pela rfc2274.

\subsection{1 - Proxies}

O uso de SNMP requer que todos os agentes, bem como as estações de gerência, suportem UDP e IP, o que limita o gerenciamento direto de dispositivos e exclui outros, tais como bridges e modems, que não suportam nenhuma parte da pilha de protocolos do TCP/IP. Além disso, existem inúmeros pequenos sistemas (PCs, workstations, controladores programáveis ) que implementam TCP/IP para suportar suas aplicações, mas para os quais não é desejável adicionar o SNMP. 


\section{Proposta de Arquitetura de Gerência para a RedUnB usando a Plataforma Tivoli TME 10}

Para acomodar dispositivos que não implementam SNMP, foi desenvolvido um conceito de proxy. Neste esquema, um agente SNMP atua como um proxy para um ou mais dispositivos, isto é o agente SNMP atua a favor dos dispositivos sob o proxy.

\subsection{2 - CMIP}

O CMIP é o protocolo para gerenciamento de redes definido pelo modelo OSI. O CMIP especifica os elementos de protocolo que são usados para prover os serviços de operação e notificação definidos pelo CMIS. É implementado num modelo orientado a objetos e baseado em eventos. Destina-se ao gerenciamento de diferentes níveis do modelo OSI, inclusive o de aplicações. Devido à sua complexidade, tem uso restrito.

\section{4 - Comparação: SNMP versus CMIP}

No gerenciamento OSI, objetos gerenciados são vistos como entidades sofisticadas com atributos, procedimentos associados e capacidades de notificação, e outras características complexas associadas com a tecnologia orientada a objetos. Para manter o SNMP simples, ele não foi projetado para trabalhar com tais conceitos sofisticados. Na verdade, os objetos no SNMP não são objetos propriamente ditos do ponto de vista da orientação a objetos; ao invés disso, objetos no SNMP são simplesmente variáveis com poucas características, tais como tipo de dados e permissões de leitura e/ou escrita.

Em relação à $\mathrm{MIB}$, as duas arquiteturas adotaram a abordagem orientada a objetos para descrever e especificar as informações nela armazenadas. No caso Internet, são definidos os objetos a serem armazenados na MIB. A ISO, por sua vez, especifica algumas classes de objetos a serem empregadas pelos sistemas de gerenciamento e fornece um guia de definição dos objetos gerenciados.

A partir dos diversos aspectos apresentados sobre as arquiteturas de gerenciamento OSI e Internet, pode-se concluir que:

- As duas arquiteturas apresentam modelos de gerenciamento similares envolvendo elementos agentes e gerentes da rede, uma MIB e um protocolo de 


\section{Proposta de Arquitetura de Gerência para a RedUnB usando a Plataforma Tivoli TME 10}

aplicação responsável pelo transporte de operações e informações de gerenciamento entre tais elementos agentes e gerente.

- No caso da arquitetura Internet, o elemento agente é muito mais simples. A sua função básica é responder às operações de gerenciamento emitidas pelo gerente. Deve-se lembrar também dos trap's na arquitetura SNMP onde os agentes enviam mensagens aos gerentes. No caso OSI, o agente tanto responde às operações como também emite notificações quaisquer de gerenciamento. Tais operações são mais complexas do que as definidas para sistemas Internet. Vale salientar também que, tanto no OSI como no SNMPv2 um elemento de rede pode exercer os papéis de agente e de gerente simultaneamente, o que não acontece no SNMP.

- No que diz respeito aos protocolos de gerenciamento, o SNMP é um protocolo não orientado à conexão que normalmente utiliza os serviços prestados pelo UDP. O CMIP é um protocolo orientado à conexão executado sobre toda pilha de protocolos OSI de gerenciamento. Dentro deste contexto, pode-se afirmar que o sistema de gerenciamento OSI apresenta um nível de confiabilidade maior em relação ao da Internet. Contudo, em determinadas situações de falhas, a simplicidade do SNMP pode representar uma eficiência maior na solução do problema ocorrido. 


\section{Proposta de Arquitetura de Gerência para a RedUnB usando a Plataforma Tivoli TME 10}

\section{3 - Conceitos de Protocolos Utilizados}

A partir deste capítulo são expostos mais detalhadamente os conceitos básicos dos protocolos e softwares utilizados para a realização das experiências que serão descritas também com mais detalhes em capítulos posteriores.

\section{1 - Gerência de Redes TCP/IP}

A necessidade de gerenciamento de redes vem fazendo com que, cada vez mais, sejam pesquisadas e desenvolvidas novas técnicas e abordagens para este tipo de problema.

Aqui, são apresentados conceitos básicos sobre gerenciamento de redes TCP/IP os protocolos utilizados, tais como, o SNMP e o SNMPv2, além da sua nova versão o SNMPv3 e também a mais importante extensão da MIB-II, o RMON. E, finalmente, são mostradas as novas abordagens e tecnologias que estão surgindo para Gerenciamento de Redes TCP/IP, procurando sempre fazer um levantamento dos pontos que estão em aberto ou que ainda não estão completamente definidos.

A área de gerência de redes foi inicialmente impulsionada pela necessidade de monitoração e controle do universo de dispositivos que compõem as redes de comunicação.

Atualmente as redes de computadores e os seus recursos associados, além das aplicações distribuídas, têm se tornado fundamental e de tal importância para uma organização, que elas basicamente "não podem falhar". Isto significa que o nível de falhas e de degradação de desempenho considerados aceitáveis está cada vez mais diminuindo, sendo este nível igual até a zero, dependendo da importância da rede para uma instituição.

Com esta crescente necessidade de gerenciamento, fez-se necessário que padrões para ferramentas fossem estabelecidos. Em resposta a esta necessidade surgiram dois padrões: 


\section{Proposta de Arquitetura de Gerência para a RedUnB usando a Plataforma Tivoli TME 10}

- Família de Protocolos SNMP: o protocolo SNMP (Simple Network Management Protocol) refere-se a um conjunto de padrões para gerenciamento que inclui um protocolo, uma especificação de estrutura de dados, e um conjunto de objetos de dados. Este protocolo hoje já está na sua segunda versão oficial, chamada de SNMPv2. E já está em desenvolvimento o SNMPv3. Este é o protocolo de gerência adotado como padrão para redes TCP/IP, e que aqui será tratado.

- Sistemas de gerenciamento OSI: este termo refere-se a um grande conjunto de padrões de grande complexidade, que definem aplicações de propósito geral para gerência de redes, um serviço de gerenciamento e protocolo, uma especificação de estrutura de dados, e um conjunto de objetos de dados. Este conjunto de protocolos é conhecido como CMIP [ISO 1991] [Stallings 1993]. Pela sua complexidade, e pela lentidão do processo de padronização, este sistema de gerenciamento não é muito popular.

\subsection{1 - Arquitetura de Gerenciamento}

O modelo utilizado para gerenciamento de redes TCP/IP é composto pelos seguintes elementos:

- Estações de Gerenciamento;

- Agente de Gerenciamento;

- Base de Informações Gerenciais (MIB);

- Protocolo de Gerenciamento de Redes.

A estação de gerenciamento serve como interface para o gerente humano num sistema de gerenciamento de rede.

$\mathrm{O}$ agente de gerenciamento responde às solicitações de informações e de ações da estação de gerenciamento e deve também prover assincronamente informações importantes que não foram solicitadas por esta estação. 


\section{Proposta de Arquitetura de Gerência para a RedUnB usando a Plataforma Tivoli TME 10}

Os recursos a serem gerenciados são representados como objetos, e a coleção destes objetos é referenciada como Base de Informações Gerenciais (MIB).

A forma de comunicação entre a estação de gerenciamento e o agente é definido pelo protocolo de gerenciamento de rede, o SNMP.

\section{2 - Simple Network Management Protocol (SNMP)}

O conjunto de padrões SNMP [Stallings 1993] [Stevens 1994] é formado por:

- Um conjunto de especificações de estrutura e identificação para as informações gerenciais. Este padrão é chamado SMI (Structure of Management Information). Estas especificações são encontradas no RFC 1155 [Rose and McGloghie 1990].

- Um protocolo de comunicação entre o gerente e o agente, chamado simplesmente de SNMP (Simple Network Management Protocol). A especificação deste protocolo e apresentada no RFC 1157 [Case et al. 1990].

- Uma base de informações gerenciais que especifica quais variáveis são mantidas pelos elementos de rede. Esta base de informações é denominada MIB (Management Information Base), e a sua segunda versão, MIB-II, está especificada pelo RFC 1213 [McGloghie and Rose 1991].

Este conjunto de padrões pode ser utilizado para outros tipos de aplicações, além daquelas convencionais de gerência. Uma utilização possível, é o uso do SNMP para fazer o Balanceamento de carga em ambientes distribuídos [Uchoa 1995].

\subsection{1 - O Protocolo SNMP}

O protocolo SNMP (descrito nos RFCs 1155, 1157, 1212, 1213) foi projetado, em meados dos anos 80, como uma resposta aos problemas de comunicação entre diversos tipos de redes. A idéia básica por trás do SNMP era oferecer uma maneira 


\section{Proposta de Arquitetura de Gerência para a RedUnB usando a Plataforma Tivoli TME 10}

facilmente implementável e com baixo overhead para o gerenciamento de roteadores, servidores, workstation e outros recursos de redes heterogêneas. No momento de sua concepção, a meta era que ele fosse apenas uma solução provisória até que surgisse um melhor projeto de protocolo para gerência de redes. Entretanto, nenhuma solução melhor tornou-se disponível.

O SNMP é um protocolo do nível de aplicação da Arquitetura TCP/IP, operando tipicamente sobre o UDP (User Datagram Protocol), uma vez que quatro, de cinco mensagens SNMP, são do tipo pergunta-resposta. Ele é considerado "simples" porque os agentes requerem um software mínimo. Muito do poder de processamento de armazenamento de dados reside no sistema de gerenciamento, enquanto um subconjunto complementar dessas funções reside no sistema gerenciado.

Como consequiência da exigência de simplicidade adotada no seu desenvolvimento, o SNMP acabou deixando de tratar algumas características, o que fez com que ele tivesse algumas deficiências (algumas destas deficiências são sanadas pelas versões 2 e 3 deste protocolo apresentadas a seguir neste relatório). Dentre essas características, destacam-se:

- Suporte para a transferência eficiente de grandes blocos de dados

- Estratégias de gerenciamento de rede centralizado

- Segurança

O protocolo SNMP define mensagens, unidades de dados chamadas PDU (Protocol Data Unit), para serem trocadas durante uma comunicação entre o gerente e o agente.

Os cinco tipos de mensagens SNMP são:

- get-request-PDU: mensagem enviada pelo gerente ao agente solicitando o valor de uma variável; 


\section{Proposta de Arquitetura de Gerência para a RedUnB usando a Plataforma Tivoli TME 10}

- get-next-request-PDU: mensagem utilizada pelo gerente para solicitar o valor da próxima variável depois de uma ou mais variáveis que foram especificadas;

- set-request-PDU: mensagem enviada pelo gerente ao agente para solicitar que seja alterado o valor de uma variável;

- get-response-PDU: mensagem enviada pelo agente ao gerente, informando o valor de uma variável que lhe foi solicitado;

- trap-PDU: mensagem enviada pelo agente ao gerente, informando um evento ocorrido.

Além de ter sido projetado para operar sob UDP, um protocolo não orientado à conexão, o próprio SNMP também é um protocolo não orientado à conexão, sendo cada troca de mensagens uma transação diferente entre $o$ agente e a estação de gerenciamento.

Cada estação de gerenciamento, como também o agente, devem implementar os protocolos SNMP e, por conseqüência, UDP e IP para poderem se comunicar. Tal imposição exclui do processo de gerenciamento dispositivos que não suportam parte dos protocolos TCP/IP, ou que, apesar de implementarem o TCP/IP para suportar suas aplicações, não desejam adicionar mais carga ao seu sistema com o suporte ao protocolo SNMP.

Para que tais dispositivos também possam ser gerenciados, criou-se o conceito de agente proxy. Desta forma, este agente, que sabe se comunicar usando SNMP, responderia em nome do dispositivo que ele representa, e passaria o resultado da comunicação para o dispositivo de acordo com o protocolo que ele entende. Para tanto, este agente possui uma função de mapeamento que recebe as informações do dispositivo que ele representa e transforma tais informações em mensagens SNMP e vice-versa.

\subsection{2 - Simple Network Management Protocol - SNMPv2}

Apesar do alto índice de aceitação, a implementação de protocolos e aplicações SNMP apresentaram deficiências, principalmente, com relação à segurança e à 


\section{Proposta de Arquitetura de Gerência para a RedUnB usando a Plataforma Tivoli TME 10}

transferência eficiente de um grande número de informações do agente para o gerente. Além disso, o SNMP não se adequa ao gerenciamento de grandes redes de computadores, devido ao fato de apresentar limitações de desempenho para obtenção de requisições explícitas, e não dar suporte à comunicação gerente-gerente.

Apenas durante o ano de 1993, foram publicadas 11 RFCs definindo revisões para o SNMP e dando início ao padrão SNMPv2, sendo o primeiro, o RFC 1441 [Case et al 1993].

Esta série de revisões trouxe consigo grandes avanços que foram incorporados ao protocolo original. Tais avanços podem ser classificados de acordo com as seguintes categorias:

- Estrutura de informação;

- Primitivas de comunicação (PDUs);

- Comunicação gerente-gerente e gerenciamento hierárquico;

- Segurança.

A estrutura de informação de gerenciamento (SMIv2) para o SNMPv2 é mais elaborada, e eliminou ambigüidades nas definições dos objetos encontrados nas especificações anteriores.

Em relação às primitivas foram acrescentados dois novos PDUs:

- get-bulk-request-PDU, que permite que uma grande quantidade de informações possa ser transferida do agente para o gerente eficientemente;

- inform-request-PDU, que permite a um gerente enviar ou eventualmente solicitar informações a outro gerente.

A comunicação gerente-gerente, como também o gerenciamento hierárquico, foram incorporados ao protocolo com a introdução do novo tipo de mensagem, informrequest; e com a SNMPv2-M2M MIB, que é constituída por dois grupos: um grupo de alerta e um grupo de eventos.

No tocante a segurança, o SNMPv2 acrescentou ao protocolo novos conceitos e serviços que trouxeram mais segurança ao protocolo. Os conceitos incluídos foram: o 


\section{Proposta de Arquitetura de Gerência para a RedUnB usando a Plataforma Tivoli TME 10}

conceito de visão de MIB definido em termos de sub-árvores, restringindo o acesso a porções pré-definidas da MIB; e o conceito de contexto, que é uma coleção de objetos e seus respectivos agentes, e a especificação dos privilégios envolvidos. Os serviços incluídos são de integridade, autenticação e confiabilidade dos dados.

\subsection{3 - Simple Network Management Protocol - SNMPv3}

É uma versão do SNMP que apresenta uma proposta de solução para o problema de segurança encontrado nas versões anteriores do protocolo. As propriedades de segurança abordadas são:

- Autenticação

Permite a um agente verificar se uma solicitação está vindo de um gerente autorizado e a integridade do seu conteúdo.

- Criptografia

Permite gerentes e agentes a criptografarem mensagens para evitar invasão de terceiros

- Controle de Acesso

Torna possível configurar agentes para oferecerem diferentes níveis de acesso a diferentes gerentes.

\section{3 - Estrutura e Identificadores das Informações Gerenciais}

A estrutura da MIB e a identificação dos objetos gerenciais são definidos no padrão chamado SMI (Structure of Management Information), encontrados no RFC 1155 [Rose and McGloghie 1990].

As definições são feitas utilizado-se um pequeno conjunto de características e elementos ASN.1. 


\section{Proposta de Arquitetura de Gerência para a RedUnB usando a Plataforma Tivoli TME 10}

\subsection{1 - Tipos de Dados}

SNMP utiliza apenas um pequeno conjunto de diferentes tipos de dados, classificados em tipos universais e tipos de aplicação.

\subsubsection{1 - Tipos Universais}

Estes são os tipos permitidos para definirem objetos da MIB. Eles são baseados na classe Universal.

- Integer (Universal 2);

- Octet String (Universal 4);

- $\quad$ Null (Universal 5);

- Object Identifier (Universal 6);

- Sequence, Sequence of (Universal 16);

\subsubsection{2 - Tipos de Aplicação}

- DisplayString: um string de 0 ou mais octetos. Cada variável deste tipo na MIB-II, não deve possuir mais de 255 caracteres;

- IpAddress: este tipo é um Octet String de tamanho 4, um para cada octeto do número IP;

- PhysAdress: um Octet String que especifica o endereço físico; 


\section{Proposta de Arquitetura de Gerência para a RedUnB usando a Plataforma Tivoli TME 10}

- Counter: um inteiro não negativo, que só pode ser incrementado e não decrementado;

- Gauge: um inteiro não negativo, que pode ser tanto incrementado como decrementado;

- TimeTicks: um inteiro não negativo, que armazena o tempo em centenas de segundos, a partir de alguma época.

\section{4 - Identificadores de Objetos}

Um identificador de um objeto é um identificador único, que consiste numa sequiência de inteiros conhecidos como sub-identificadores.

A sequiência, lida da esquerda para a direita, define a localização deste objeto na estrutura de árvore da MIB.

\section{5 - Estrutura da MIB}

Associado a cada um dos objetos da MIB, está o seu identificador, que nomeia este objeto. Esta identificação segue uma estrutura hierárquica, cuja convenção também serve para identificar os tipos dos objetos.

O documento SMI, define quatro nodos abaixo do nodo Internet:

- $\quad$ directory: esta sub-árvore é reservada para o uso futuro do X.5001;

- $\quad m g m t$ : esta sub-árvore é utilizada para os objetos gerenciados definidos em documentos IAB aprovados;

- experimental: esta sub-árvore é utilizada para identificadores de objetos gerenciados usados em experiências na Internet;

- private: esta sub-árvore está reservada para a utilização de identificadores de objetos gerenciados definidos unilateralmente, por exemplo, por fabricantes que desejem ter seus próprios objetos. 


\section{Proposta de Arquitetura de Gerência para a RedUnB usando a Plataforma Tivoli TME 10}

\section{6 - Base de Informações Gerenciais}

A MIB é uma base de dados, cuja estrutura é especificada pelo padrão SMI, como já descrito anteriormente.

Ela pode ser caracterizada como um banco de dados ativo, o que possibilita que os valores das suas variáveis sejam, não só recuperados, como também alterados.

Cada agente deve manter sua própria instancia da MIB, relacionada com os objetos que estão sendo gerenciados sob o seu domínio. O RFC 1213, define um conjunto de variáveis utilizadas para a monitoração e o controle de redes TCP/IP.

Para cada novo dispositivo a ser gerenciado, que não tenha sido previsto o seu gerenciamento, é necessário que seja definido um conjunto de novas variáveis, estendendo assim, a MIB-II original.

\section{7 - Remote Network Monitoring MIB (RMON)}

O protocolo SNMP não é adequado para ambientes de redes corporativas e constituídas de diversas redes locais conectadas através de outra de longa distância. Esses enlaces de rede de longa distância, por operarem a taxas de transmissão inferiores às LANs que a interconectam, passam a ter grande parte da sua banda de transmissão ocupada para informações de gerenciamento. Uma solução encontrada para dirimir este problema foi o Remote MONitoring (RMON).

RMON é uma capacidade de gerenciamento remoto do SNMP. A especificação RMON é uma definição de uma MIB. Seu objetivo, contudo, é definir padrões de monitoração e interfaces para a comunicação entre agentes/gerentes SNMP.

RMON dá ao gerente da rede a habilidade para monitorar sub-redes como um todo, ao invés de apenas dispositivos individuais na sub-rede.

O protocolo RMON oferece suporte à implementação de um sistema de gerenciamento distribuído. Nele fica atribuída aos diferentes elementos, tais como 


\section{Proposta de Arquitetura de Gerência para a RedUnB usando a Plataforma Tivoli TME 10}

estações de trabalho, hubs, switches ou roteadores, das redes locais remotas a função de monitorar remotamente. Cada elemento RMON tem, então, como tarefas, coletar, analisar, tratar e filtrar informações de gerenciamento da rede e apenas notificar à estação gerente os eventos significativos e situações de erro.

No caso de existirem múltiplos gerentes, cada elemento RMON deve determinar quais informações de gerenciamento devem ser encaminhados para cada gerente.

Sendo assim, os objetivos do protocolo RMON são:

- Reduzir a quantidade de informações trocadas entre a rede local gerenciada e a estação gerente conectada a uma rede local remota.

- Possibilitar o gerenciamento contínuo de segmentos de redes locais, mesmo quando a comunicação entre o elemento RMON e a estação gerente estiver, temporariamente, interrompida.

- Permitir o gerenciamento pró-ativo da rede, diagnosticando e registrando eventos que possibilitem detectar o mau funcionamento e prever falhas que interrompam sua operação.

- Detectar, registrar e informar à estação gerente condições de erro e eventos significativos da rede.

- Enviar informações de gerenciamento para múltiplas estações gerentes, permitindo, no caso de situações críticas de operação da rede gerenciada, que a causa da falha ou mau funcionamento da rede possa ser diagnosticada a partir de mais de uma estação gerente.

Dois padrões básicos de protocolo RMON são especificados: RMON1 e RMON2, funcionalmente complementares.

\subsection{1 - RMON1}

O RMON1 opera somente na camada Media Access Control (MAC) oferecendo recursos ao administrador da rede para monitorar o tráfego e coletar informações e estatísticas da operação de um segmento de rede local, além de realizar o diagnóstico 


\section{Proposta de Arquitetura de Gerência para a RedUnB usando a Plataforma Tivoli TME 10}

remoto de falhas e erros ocorridos no segmento de rede a partir de funcionalidades de um analisador de protocolo suportadas pelo correspondente elemento RMON.

Porém, o fato do RMON1 só trabalhar na camada MAC, significa que este somente apresenta estatísticas para tráfego agregado - porém não apresenta estatísticas para camadas diferentes de várias pilhas de protocolos (ex. IP, FTP, IPX). Isto também significa que, por não ser capazes de monitorar a camada de rede, os dispositivos RMON1 não distinguem o tráfego originado através de um roteador, o que é uma grande deficiência.

\subsection{2 - RMON2}

O RMON2, por sua vez, opera no nível da camada de rede e camadas superiores, complementando portanto o RMON1, possibilitando coletar informações estatísticas e monitorar a comunicação fim-a-fim e o tráfego gerado por diferentes tipos de aplicação. A Figura 3.1 a seguir ilustra esta diferença.

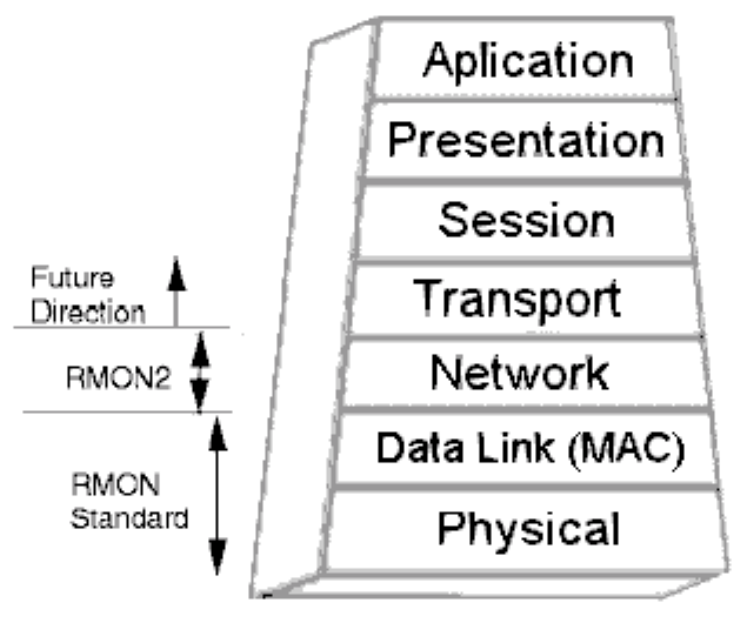

Figura 3.1 - Diferença entre RMON e RMON2

Com a utilização do padrão RMON original, um monitor RMON pode monitorar o tráfego de rede ao qual está conectado, mas não pode saber de onde está provindo originalmente este tráfego, nem tão pouco o destino final. Para tentar solucionar esta deficiência, foi criado um grupo de trabalho para desenvolver o padrão RMON2, gerando dois internet drafts: Remote Network Monitoring MIB Version 2 [Waldbusser 1996] e Remote Network Monitoring MIB Protocol Identifiers [Bierman e Iddon 1996]. 


\section{Proposta de Arquitetura de Gerência para a RedUnB usando a Plataforma Tivoli TME 10}

Um monitor RMON2 não está limitado a monitorar e decodificar o tráfego da camada de rede [Stallings 1996]. Ele também pode ver os protocolos de alto nível rodando acima da camada de rede, determinando, assim, que protocolos da camada de aplicação estão gerando este tráfego. Um gerente necessita, periodicamente, consultar os monitores para obter informações. Seria interessante, para efeitos de eficiência, que apenas os dados que foram alterados desde a última consulta fossem retornados. Para possibilitar tal facilidade, o RMON2 criou o conceito de filtragem de tempo (time filtering), introduzindo um time stamp em cada linha, que armazena a última vez em que esta foi alterada.

\subsection{3 - Controle de Monitoramento Remoto}

Com o objetivo de efetivamente gerenciar um monitor remoto, a RMON MIB contém características que possibilitam o controle efetivo da estação de gerenciamento. Estas características podem ser agrupadas em duas categorias:

- Configuração: tabelas de controle e tabelas de dados;

- Invocação de uma ação: um objeto utilizado para representar um comando, e uma invocação de uma ação pode ser solicitada modificando o valor de um objeto.

\subsection{4 - Múltiplos Gerentes}

$\mathrm{Na}$ arquitetura $\mathrm{RMON}$, agentes podem estar sujeitos ao gerenciamento de muitas estações gerentes. No caso de um agente RMON ser compartilhado alguns problemas podem surgir, são eles:

- Requisições concorrentes;

- Captura de um recurso por um determinado gerente por um longo período de tempo;

- Recursos podem ser atribuídos para um gerente que deu pane antes de liberar o recurso. 


\section{Proposta de Arquitetura de Gerência para a RedUnB usando a Plataforma Tivoli TME 10}

Para tentar solucionar tais problemas uma combinação de requisitos devem ser utilizados, são eles:

- Inclusão de um campo de dono para cada linha da tabela de controle;

- Reconhecimento da não necessidade de utilização de um recurso;

- Possibilidade de negociação de um recurso entre gerentes;

- A possibilidade de um operador cancelar reservas de recursos;

- Durante uma reinicialização, um gerente pode liberar recursos.

\subsection{5 - Gerenciamento de Tabelas}

Um outro grande avanço introduzido com o padrão RMON, foi o gerenciamento de tabelas, atividade que não era muito clara no padrão SNMP original. A especificação RMON inclui convenções textuais e regras mais claras e disciplinadas para a adição e remoção de linhas.

\section{8 - MIB}

Neste novo capítulo entraremos em mais detalhes sobre as Management Information Base nas versões I e II, MIB I e MIB II.

O conhecimento das MIB's (Base de Informações Gerenciáveis), e principalmente, o conhecimento de como utilizar estas informações, são de fundamental importância na Gerência de Redes.

Antes de definir o que é uma MIB, será introduzido o conceito de objetos gerenciados.

\subsection{1 - Objeto gerenciado}

Um objeto gerenciado é a visão abstrata de um recurso real do sistema. Assim, todos os recursos da rede que devem ser gerenciados são modelados, e as estruturas de dados resultantes são os objetos gerenciados. Os objetos gerenciados podem ter 


\section{Proposta de Arquitetura de Gerência para a RedUnB usando a Plataforma Tivoli TME 10}

permissões para serem lidos ou alterados, sendo que cada leitura representará o estado real do recurso e, cada alteração também será refletida no próprio recurso.

Dessa forma, a MIB (Management Information Base) é o conjunto dos objetos gerenciados, que procura abranger todas as informações necessárias para a gerência da rede, possibilitando assim, a automatização de grande parte das tarefas de gerência. A árvore MIB II:

A MIB II usa uma arquitetura de árvore, definida na ISO ASN.1, para organizar todas as suas informações. Cada parte da informação da árvore é um nó rotulado que contém:

- um identificador de objetos (OID): seqüência de números separados por pontos.

- uma pequena descrição textual: descrição do nó rotulado

Um nó rotulado pode ter sub-árvores contendo outros nós rotulados. Caso não tenha sub-árvores, ou nós folhas, ele conterá um valor e será um objeto.

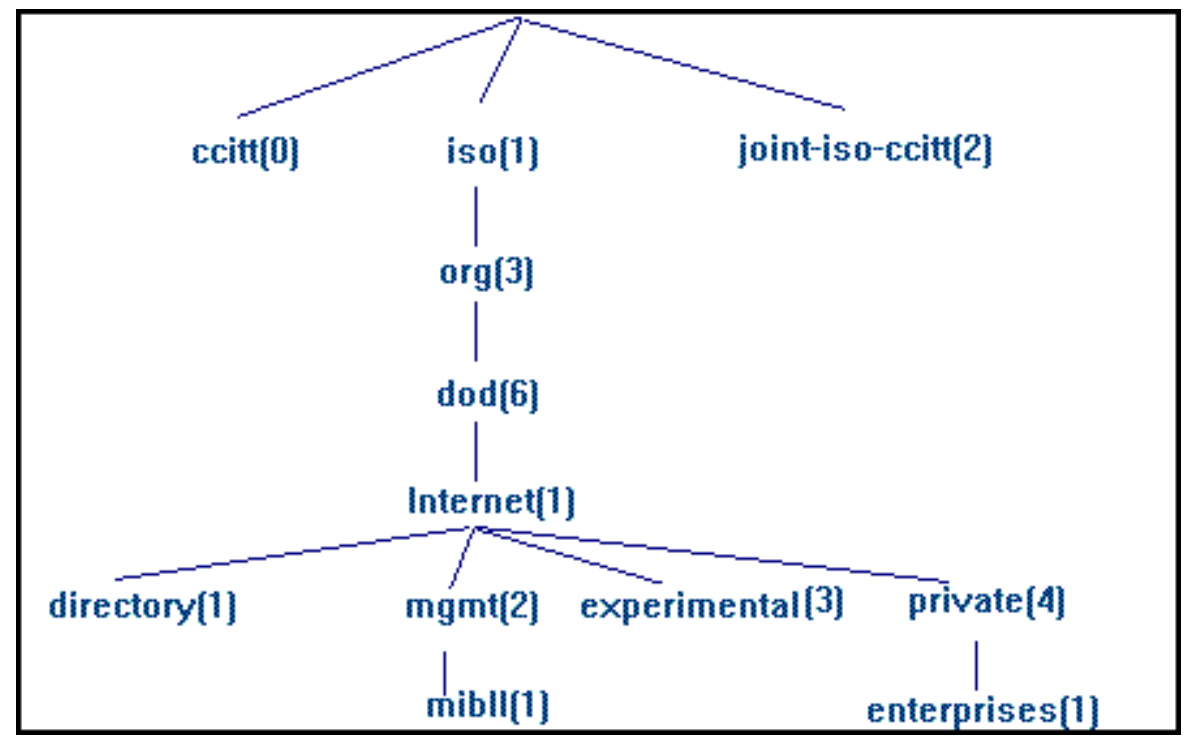

Figura 3.2 - Árvore MIB II

O nó raiz da árvore MIB não tem nome ou número, mas tem três sub-árvores:

1. $\operatorname{ccitt}(\mathbf{0})$, administrada pelo CCITT

2. iso(1), administrada pela ISO

3. joint-iso-ccitt(2), administrada pela ISO juntamente com o CCITT. 


\section{Proposta de Arquitetura de Gerência para a RedUnB usando a Plataforma Tivoli TME 10}

Sob o nó iso(1), estão outras sub-árvores, como é o caso da sub-árvore org(3), definida pela ISO para conter outras organizações. Uma das organizações que está sob a sub-árvore org(3) é o Departamento de Defesa dos EUA (DOD), no nó dod(6). A Internet(1) está sob o dod(6), e possui quatro sub-árvores:

- $\quad$ directory(1): contém informações sobre o serviço de diretórios OSI (X.500)

- $\quad \operatorname{mgmt}(2)$ : contém informações de gerenciamento, é sob esta sub-árvore que está o nó da MIBII, com o identificador de objeto 1.3.6.1.2.1 ou \{mgmt 1$\}$.

- $\quad$ experimental(3): contém os objetos que ainda estão sendo pesquisados pela IAB.

- $\quad$ private(4): contém objetos definidos por outras organizações.

Abaixo da sub-árvore MIBII estão os objetos usados para obter informações específicas dos dispositivos da rede. Esses objetos são divididos em 11 grupos, que são apresentados na tabela abaixo.

\begin{tabular}{|l|l|}
\hline Grupos & Informações \\
\hline system(1) & sistema de operação dos dispositivos da rede \\
\hline interfaces(2) & interface da rede com o meio físico \\
\hline Address translation(3) & mapeamento de endereços IP em endereços físicos \\
\hline $\operatorname{ip}(4)$ & protocolo IP \\
\hline icmp(5) & protocolo ICMP \\
\hline tcp(6) & protocolo TCP \\
\hline udp(7) & protocolo UDP \\
\hline egp(8) & protocolo EGP \\
\hline $\operatorname{cmot}(9)$ & protocolo CMOT \\
\hline transmission(10) & meios de transmissão \\
\hline snmp(11) & protocolo SNMP \\
\hline
\end{tabular}

Tabela 3.1 - Grupos de objetos usados pela MIB II

Cada objeto contido nos grupos apresentados na tabela acima é descrito no RFC1213. A descrição dos objetos é dividida em cinco partes: o nome do objeto, a sintaxe abstrata do objeto, a descrição textual do significado do objeto, o tipo de acesso 


\section{Proposta de Arquitetura de Gerência para a RedUnB usando a Plataforma Tivoli TME 10}

permitido ao objeto (read-only, read-write, write-only ou não acessível), e o estado do objeto (obrigatório, opcional, obsoleto).

\subsection{2 - O Grupo SYSTEM}

Este grupo contém informações sobre o sistema no qual se encontra a entidade gerenciada. Muitos destes objetos são usados no gerenciamento de configuração e gerenciamento de falhas.

\section{Objetos do Grupo System para Gerenciamento de Configuração}

\begin{tabular}{|l|l|}
\hline Objeto & Informação usada no gerenciamento de configuração \\
\hline sysDescr & descrição do sistema \\
\hline sysLocation & localização física do sistema \\
\hline sysContact & pessoa responsável pelo sistema \\
\hline sysName & nome do sistema \\
\hline
\end{tabular}

Tabela 3.2 - Objetos para Gerenciamento de Configuração (System)

O sysDescr informa a descrição do sistema. Este dado pode ser útil tanto para gerenciar a configuração do dispositivo como para diagnosticar falhas.

Os objetos sysLocation, sysContact e sysName informam respectivamente , a localização física do sistema, a pessoa de contato em caso de problemas, e o nome do dispositivo da rede. Estas informações são úteis quando há necessidade de contactar com alguém para um acesso físico a um dispositivo remoto.

\section{Objetos do Grupo System para Gerenciamento de Falhas}

\begin{tabular}{|l|l|}
\hline Objeto & Informação usada no gerenciamento de falhas \\
\hline sysObjectID & fabricante do sistema \\
\hline sysServices & qual camada de protocolo o sistema serve \\
\hline sysUpTime & quanto tempo o sistema está operacional \\
\hline
\end{tabular}

Tabela 3.3 - Objetos para Gerenciamento de Falhas (System) 


\section{Proposta de Arquitetura de Gerência para a RedUnB usando a Plataforma Tivoli TME 10}

O identificador de objeto encontrado em sysObjectID informa o fabricante do sistema. Este dado é importante para resolver um problema de um dispositivo, quando necessita conhecer o seu fabricante.

O sysServices informa quais os níveis do modelo de referência da ISO, o dispositivo serve. Retorna a soma dos números de cada camada, usando, para cada camada, a fórmula $2^{(\mathrm{L}-1)}$, onde $\mathrm{L}$ é o número da camada. Esta informação é útil para rastrear problemas quando a funcionalidade do dispositivo é desconhecida.

O sysUptime informa a quanto tempo um sistema está funcionando. Através deste objeto, a aplicação de gerenciamento de falhas pode determinar se o sistema foi restaurado desde a última vez que o objeto foi consultado.

\subsection{3 - O Grupo Interfaces}

O Grupo Interfaces oferece dados sobre cada interface de um dispositivo gerenciável da rede. Essas informações são úteis para o gerenciamento de falhas, de configuração, de performance, e de contabilização.

O objeto ifTable contém informações sobre todas as interfaces de uma entidade.

\section{Objetos para Gerenciamento de Falhas}

\begin{tabular}{|l|l|}
\hline Objeto & Informação usada no gerenciamento de falhas \\
\hline if AdminStatus & indica se a interface está administrativamente up/down/test \\
\hline ifOper Status & indica o status operacional da interface (up/down/test) \\
\hline if Last Change & indica quando a interface mudou seu estado operacional \\
\hline
\end{tabular}

Tabela 3.4 - Objetos para Gerenciamento de Falhas (Interfaces) 


\section{Proposta de Arquitetura de Gerência para a RedUnB usando a Plataforma Tivoli TME 10}

A combinação dos objetos ifAdminStatus e ifOperStatus determina o status da interface. A tabela abaixo apresenta as possíveis combinações.

- IfAdminStatus

- Up(1) Down(2) Testing(3)

- ifOperStatus

$\bullet$

- $\boldsymbol{U p}(1)$ Operacional N/A N/A

- Down(2) Falha Down N/A

- Testing(3) N/A N/A em teste

-

- N/A - não aplicável.

O objeto ifLastChange informa quando a interface entrou no seu estado operacional atual.

\section{Objetos para Gerência de Configuração}

\begin{tabular}{|l|l|}
\hline Objeto & Informação usada no gerenciamento de configuração \\
\hline if Descr & nome da interface \\
\hline IfType & tipo de interface \\
\hline IfMtu & tamanho máximo do datagrama suportado pela interface \\
\hline IfSpeed & largura de banda da interface \\
\hline if AdminStatus & indica se a interface esta administrativamente up/down/test \\
\hline
\end{tabular}

Tabela 3.5 - Objetos para Gerência de Configuração (Interfaces)

- o objeto ifDescr nomeia a interface

- o objeto ifType atribui um tipo a interface

- o objeto ifSpeed é um medidor da velocidade da interface em bits por segundo.

Útil quando deseja-se saber a velocidade atual de uma interface que aloca banda passante de acordo com a demanda de tráfego. 


\section{Proposta de Arquitetura de Gerência para a RedUnB usando a Plataforma Tivoli TME 10}

- o objeto ifAdminStatus permite que, através do comando SNMP Set-Request, configure-se remotamente a interface para on/off.

\section{Objetos para Gerência de Performance}

\begin{tabular}{|l|l|}
\hline Objeto & Informação usada no gerenciamento de Performance \\
\hline if InDiscards & taxa de descartes de entrada \\
\hline ifOutDiscards & taxa de descartes de saída \\
\hline ifInErrors & taxa de erros de entrada \\
\hline ifOutErros & taxa de erros de saída \\
\hline ifInOctets & taxa de bytes recebidos \\
\hline ifOut Octets & taxa de bytes enviados \\
\hline ifInUcastPkts & taxa de pacotes unicast recebidos \\
\hline ifOutUcastPkts & taxa de pacotes unicast enviados \\
\hline ifInNUcastPkts & taxa de pacotes no-unicast recebidos \\
\hline ifOutNucastPkts & taxa de pacotes no-unicast enviados \\
\hline ifInUnknownProtos & taxa de pacotes de protocolos desconhecidos recebidos \\
\hline ifOutQLen & total de pacotes na fila de saída \\
\hline & Tabela 3.6 - Objetos para Gerência de Performance (Interfaces) \\
\hline
\end{tabular}

Com os objetos ifInUcastPkts, ifOutUcastPkts, ifInNUcastPkts, ifOutNucastPkts, ifInErrors, ifOutErros, podemos calcular as porcentagens de erro de entrada/saída.

porcentagem de erro de entrada $=$ ifInErrors $/($ ifInUcastPkts + ifInNUcastPkts $)$ porcentagem de erro de saída $=$ ifOutErrors $/$ (ifOutUcastPkts + ifOutNUcastPkts)

- da mesma forma, com os objetos ifInUcastPkts, ifOutUcastPkts, ifInNUcastPkts, ifOutNucastPkts, ifInDiscards, ifOutDiscards, podemos calcular as porcentagens de descartes de entrada/saída.

- o objeto ifInUnknownProtos informa o número de descartes realizados devido ao recebimento de pacotes de protocolo desconhecido. Portanto não há a 


\section{Proposta de Arquitetura de Gerência para a RedUnB usando a Plataforma Tivoli TME 10}

detecção de nenhum problema, caso o valor dos objetos ifInUnknownProtos e ifInDiscards estiverem crescendo proporcionalmente.

- com os objetos ifInOctets e ifOut Octets pode-se calcular a taxa de utilização de uma interface.

primeiro calcula-se o total de bytes recebidos e enviados em um intervalo de tempo entre $x$ e $y$

total de bytes $=($ ifInOctets_y - ifInOctets_x $)+($ ifOutOctets_y - ifOutOctets_x $)$

depois calcula-se o total de bytes por segundo

total de bytes por segundo $=$ total de bytes $/(\mathrm{y}-\mathrm{x})$

calcula-se o total de bits por segundo

total de bits por segundo $=$ total de bytes por segundo $* 8$

finalmente tem-se a taxa de utilização

taxa de utilização $=($ total de bits por segundo $) /$ ifSpeed

- o objeto ifOutQLen indica se o dispositivo está tendo problemas em enviar dados para fora. Seu valor aumenta de acordo com o aumento do número de pacotes esperando para deixar a interface.

- os objetos ifOutOctets e ifOutDiscards juntos podem sinalizar um congestionamento na rede. Isto ocorre no caso de houver um aumento no valor do ifOutDiscards devido ao descarte de muitos pacotes que tentam deixar a interface, e uma diminuição do número total de bytes de saída, indicado pelo objeto ifOutOctets

\section{Objetos para Gerência de Contabilização}

\begin{tabular}{|l|l|}
\hline Objeto & Informação usada no gerenciamento de Contabilização \\
\hline ifInOctets & taxa de bytes recebidos \\
\hline ifOut Octets & taxa de bytes enviados \\
\hline ifInUcastPkts & taxa de pacotes unicast recebidos \\
\hline ifOutUcastPkts & taxa de pacotes unicast enviados \\
\hline ifInNUcastPkts & taxa de pacotes no-unicast recebidos \\
\hline ifOutNucastPkts & taxa de pacotes no-unicast enviados \\
\hline
\end{tabular}

Tabela 3.7 - Objetos para Gerência de Contabilização (Interfaces) 


\section{Proposta de Arquitetura de Gerência para a RedUnB usando a Plataforma Tivoli TME 10}

Com os objetos ifInOctets e ifOut Octets, uma aplicação de gerenciamento de contabilização pode determinar o número de bytes enviados e recebidos em uma interface. se a unidade de contabilização utilizada tratar-se de pacotes ao invés de bytes, são utilizados os objetos ifInUcastPkts, ifOutUcastPkts, ifInNUcastPkts, ifOutNucastPkts para calcular o número de pacotes recebidos e enviados.

\subsection{4 - O Grupo Address Translation}

O grupo Address Translation não constitui mais um grupo separado. Seus objetos foram incorporados aos grupos de protocolos. Portanto o uso de informações de conversão de endereços no gerenciamento de redes serão analisados em cada um desses grupos.

\subsection{5 - O Grupo IP}

O IP é um protocolo de rede que utiliza um modo de serviço sem conexão para entregar datagramas. O grupo IP provê informações sobre o protocolo IP na entidade. Estas informações são subdivididas em quatro grupos:

1. objetos que informam erros e tipos dos pacotes IP vistos

2. tabela de informação sobre os endereços IP das entidades

3. tabela de roteamento IP da entidade

4. mapeamento de endereços IP para outros protocolos (substituindo o grupo Address Translation)

Os objetos do grupo IP podem ser aplicados ao gerenciamento de falhas, de configuração, de performance, e de contabilização.

\section{Objetos para Gerenciamento de Falhas}

\begin{tabular}{|l|l|}
\hline Objeto & Informação usada no gerenciamento de Falhas \\
\hline ipRoutTable & tabela de roteamento IP \\
\hline ipNetToMediaTable & tabela de conversão de endereços IP \\
\hline
\end{tabular}

Tabela 3.8 - Objetos para Gerenciamento de Falhas (Translation) 


\section{Proposta de Arquitetura de Gerência para a RedUnB usando a Plataforma Tivoli TME 10}

Os objetos apresentados na tabela 3.8 são utilizados no gerenciamento de falhas.

O ipRoutTable é uma tabela que possui as seguintes colunas:

- ipRouteDest: endereço IP do destino

- ipRouteIfIndex: número da interface

- ipRouteMetric1: métrica de roteamento \#1

- ipRouteMetric2: métrica de roteamento \#2

- ipRouteMetric3: métrica de roteamento \#3

- ipRouteMetric4: métrica de roteamento \#4

- ipRouteMetric5: métrica de roteamento \#5

- ipRouteNextHop: próxima escala (endereço IP do roteador, usado para roteamento indireto)

- ipRouteType: tipo(direto, indireto, válido, inválido)

- ipRouteProto: mecanismo usado para determinar a rota

- ipRouteAge: idade da rota em segundos

- ipRouteMask: máscara da subrede para roteamento

- ipRouteInfo: ponteiro MIB para um protocolo de roteamento específico

Todos os objetos contidos no objeto ipRouteTable pode ser usado no gerenciamento de falhas. Por exemplo, eles podem ser usados para rastrear problemas de roteamento e de dispositivos que sinalizam informações de roteamento incorreto. Esses objetos permitem que a aplicação de gerenciamento de falhas produza a tabela de roteamento IP para um dispositivo e descubra rotas através da rede. Além disso os objetos ipRouteType e IpRouteProto informam como a informação de roteamento foi aprendida.

Assim como o ipRouteTable, o objeto IpNetToMediaTable é uma tabela com as seguintes entradas:

- ipNetToMediaIfIndex: número da interface

- ipNetToMediaPhysAddress: endereço do meio do mapeamento

- ipNetToMediaNetAddress: endereço IP do mapeamento

- ipNetToMediaType: como o mapeamento foi determinado (outro, inválido, dinâmico, estático) 


\section{Proposta de Arquitetura de Gerência para a RedUnB usando a Plataforma Tivoli TME 10}

Os objetos contidos no objeto IpNetToMediaTable informam o mapeamento de endereços IP para endereços em outros protocolos.

\section{Objetos para Gerenciamento de Configuração}

\begin{tabular}{|l|l|}
\hline Objeto & Informação usada no gerenciamento de Configuração \\
\hline IpFowarding & se o dispositivo é setado para IP \\
\hline IpAddrTable & endereços IP do dispositivo \\
\hline IpRouteTable & tabela de roteamento IP \\
\hline
\end{tabular}

Tabela 3.9 - Objetos para Gerenciamento de Configuração (Translation)

Os objetos da tabela 3.9 são utilizados no gerenciamento de configuração.

- o objeto ipForwarding indica se a entidade está configurada para enviar (forward) datagramas IP.

- o objeto IpAddrTable é composto dos seguintes objetos:

○ ipAdEntAddr: o endereço IP desta entrada

- ipAdEntIfIndex: número da interface

- ipAdEntNetMask: máscara de sub-rede para endereços IP

- ipAdEntBcastAddr: o bit menos significativo do endereço IP de broadcast

Estes dados são definidos na MIB somente para leitura (read-only), portanto a aplicação de gerenciamento de configuração poderá apenas consultá-los e não alterá-los.

- já o objeto ipRouteTable possui vários objetos definidos com permissão de leitura e escrita ( read-write). Dessa forma, uma aplicação de gerenciamento de configuração pode entrar com novas rotas através do objeto ipRouteDest e mudar o tipo de uma rota com o objeto ipRouteType. Além disso é possível configurar-se as métricas de roteamento através dos objetos ipRouteMetric1, ipRouteMetric2, ipRouteMetric3, ipRouteMetric4 e ipRouteMetric5. 


\section{Proposta de Arquitetura de Gerência para a RedUnB usando a Plataforma Tivoli TME 10}

\section{Objetos para Gerenciamento de Performance}

\begin{tabular}{|l|l|}
\hline Objeto & Informação usada no gerenciamento de Performance \\
\hline IpInReceives & taxa de datagramas de recebidos \\
\hline IpInHdrErrors & taxa de erros de cabeçalho de entrada \\
\hline IpInAddrErrors & taxa de erros de endereço de entrada \\
\hline IpForwDatagrams & taxa de datagramas repassados \\
\hline IpInUnknownProtos & taxa de datagramas de entrada para um protocolo desconhecido \\
\hline IpInDiscards & taxa de datagramas de entrada descartados \\
\hline IpInDelivers & taxa de datagramas de entrada entregues com sucesso \\
\hline IpOutRequests & taxa de datagramas de saída (não inclui os datagramas repassados) \\
\hline IpOutDiscards & taxa de datagramas de saída descartados \\
\hline ipOutNoRoutes & taxa de descartes ocorridos por falta de informação de roteamento \\
\hline ipRoutingDiscards & taxa de entradas de roteamento descartadas \\
\hline ipReasmReqds & taxa de datagramas recebidos necessitando de remontagem \\
\hline ipReasmOKs & taxa de datagramas com sucesso na remontagem \\
\hline ipReasmFails & taxa de datagramas com falhas na remontagem \\
\hline ipFragOKs & taxa de datagramas com sucesso na fragmentação \\
\hline ipFragFails & taxa de datagramas com insucesso na fragmentação \\
\hline ipFragCreates & taxa de fragmentos gerados \\
\hline
\end{tabular}

Tabela 3.10 - Objetos para Gerenciamento de Performance (Translation)

Os objetos listados na tabela 3.10 podem ser usados no gerenciamento de performance. A seguir serão apresentadas algumas das formas que estes objetos podem ser utilizados para auxiliar no gerenciamento de performance.

- os objetos ipInReceives e ipOutRequest juntamente com alguns objetos do grupo Interface permitem o cálculo da taxa de tráfego IP de entrada e saída de uma entidade:

porcentagem de tráfego ip de entrada: (ifInUcastPkts + ifInNUcastPkts) / ipInReceives 


\section{Proposta de Arquitetura de Gerência para a RedUnB usando a Plataforma Tivoli TME 10}

porcentagem de tráfego ip de saída: (ifOutUcastPkkts + ifOutNUcastPkts) / ipOutRequest

- $\quad$ pode-se calcular a porcentagem de erros de datagramas IP:

porcentagem de erros de entrada:

(ipInDiscards+ipInHdrErrors+ipInAddrErrors)/ipInReceives porcentagem de erros de saída:

(ipOutDiscards+ipOutHdrErrors+ipOutAddrErrors)/ipOutRequests

- o aumento do valor do objeto ipRoutingDiscards pode significar que um dispositivo está descartando entradas válidas devido à falta de recursos.

- um freqüente aumento no valor do objeto ipInUnknownProtos pode causar problemas de performance, pois os recursos estarão sendo desperdiçados em checagens de erros e determinação do destino, sendo que por fim o datagrama será descartado por ser destinado a um protocolo da camada superior desconhecido.

- pode-se calcular a taxa de forwarding e de recepção de datagramas IP por um dispositivo em um intervalo tempo entre $x$ e $y$ em segundos.

taxa de forwarding $=($ ipForwDatagrams_y - ipForwDatagrams_x $) /(y-x)$ taxa de entrada $=($ ipInReceives_y - ipInReceives_x $) /(y-x)$

Tendo estas duas taxas pode-se determinar se o sistema está repassando os datagramas IP rápido o bastante para satisfazer os requerimentos da rede. Se os pacotes recebidos estão sendo repassados a outros sistemas, a taxa de entrada e taxa de forwarding devem ser iguais. No entanto para que o cálculo seja mais exato deve-se subtrair da taxa de entrada a taxa de erros e pacotes IP destinados ao próprio sistema. 
Proposta de Arquitetura de Gerência para a RedUnB usando a Plataforma Tivoli TME 10

\section{Objetos para Gerenciamento de Contabilização}

\begin{tabular}{|l|l|}
\hline Objeto & Informação usada no gerenciamento de Performance \\
\hline ipOutRequests & numero de pacotes IP enviados \\
\hline ipInReceives & numero de pacotes IP recebidos \\
\hline ipInDelivers & numero de pacotes IP de entrada entregues com sucesso \\
\hline
\end{tabular}

Tabela 3.11 - Objetos para Gerenciamento de Contabilização (Translation)

A tabela 3.11 contém os objetos do grupo IP usados para auxiliar no gerenciamento de contabilização

- os objetos ipOutRequests e ipInReceives informam o número total de pacotes IP enviados e recebidos por uma entidade.

- o objeto ipInDelivers informa o número de pacotes IP entregues com sucesso a protocolos de camada superior e aplicações.

\subsection{6 - O Grupo ICMP}

O ICMP é um protocolo que carrega mensagens de erro e controle para dispositivos IP. O grupo ICMP contém objetos que fornecem informações sobre o protocolo ICMP na entidade em questão. Todos os seus objetos são aplicados ao gerenciamento de performance. 


\section{Proposta de Arquitetura de Gerência para a RedUnB usando a Plataforma Tivoli TME 10}

Os objetos do grupo ICMP são apresentados na tabela abaixo:

\begin{tabular}{|c|c|}
\hline Objeto & Informação usada para gerenciamento de performance \\
\hline icmpInMsgs & taxa de recebimento de mensagens \\
\hline icmpInErrors & taxa de erros de entrada \\
\hline icmpInDestUnreachs & taxa de mensagens de Destino não Alcançado recebidas \\
\hline icmpInTimeExcds & taxa de mensagens de Tempo Excedido recebidas \\
\hline icmpInParmProbs & taxa de mensagens de Problemas com Parâmetros recebidas \\
\hline icmpInSrcQuenchs & taxa de mensagens de Fonte Apagada recebidas \\
\hline icmpInRedirects & taxa de mensagens de Redirecionamento recebidas \\
\hline icmpInEchos & taxa de mensagens de Ecos (requisição)recebidas \\
\hline icmpInEchoReps & taxa de mensagens de Respostas a Ecos recebidas \\
\hline icmpInTimestamps & taxa de mensagens de icmpInTimestampReps \\
\hline icmpInAddrMasks & $\begin{array}{l}\text { taxa de mensagens de Requisição de Máscaras de Endereços } \\
\text { recebidas }\end{array}$ \\
\hline icmpInAddrMaskReps & taxa de mensagens de Resposta a Máscaras de Endereços recebidas \\
\hline icmpOutMsgs & taxa de saída de mensagens \\
\hline icmpOutErrors & taxa de erros de saída \\
\hline icmpOutDestUnreachs & taxa de mensagens de Destino não Alcançado enviadas \\
\hline icmpOutTimeExcds & taxa de mensagens de Tempo Excedido enviadas \\
\hline icmpOutParmProbs & taxa de mensagens de Problema com Parâmetros enviadas \\
\hline icmpOutSrcQuenchs & taxa de mensagens de Origem Apagada enviadas \\
\hline icmpOutRedirects & taxa de mensagens de Redirecionamento enviadas \\
\hline icmpOutEchos & taxa de mensagens de Eco(requisição)enviadas \\
\hline icmpOutEchoReps & taxa de mensagens Respostas de Eco enviadas \\
\hline icmpOutTimestamps & taxa de mensagens de requisição de Timestamp enviadas \\
\hline icmpOutTimestampReps & taxa de mensagens de respostas ao pedido de Timestamp enviadas \\
\hline icmpOutAddrMasks & taxa de mensagens de Requisição de Máscara de Endereços enviadas \\
\hline icmpOutAddrMaskReps & taxa de mensagens de Resposta de Máscara de Endereços enviadas \\
\hline
\end{tabular}

Tabela 3.12 - Objetos do Grupo ICMP 


\section{Proposta de Arquitetura de Gerência para a RedUnB usando a Plataforma Tivoli TME 10}

\subsection{7 - O Grupo TCP}

O TCP é um protocolo de transporte que provê conexões confiáveis entre aplicações. Muitas implementações do TCP incluem recursos adicionais para lidar com controle de fluxo, congestionamento da rede, e a retransmissão de segmentos perdidos. O grupo TCP pode ajudar no gerenciamento de configuração, performance, de contabilização, e de segurança.

Este grupo é subdividido em dois grupos:

1. objetos gerais sobre o TCP no sistema

2. uma tabela de valores para cada conexão TCP corrente, a qual é alterada a cada começo e fím de uma conexão TCP.

\section{Objetos para Gerenciamento de Configuração}

\begin{tabular}{|l|l|}
\hline Objeto & Informação usada para gerenciamento de Configuração \\
\hline tcpRtoAlgorithm & $\begin{array}{l}\text { algoritmo utilizado para determinar o "time out" de retransmissão de } \\
\text { octetos TCP não confirmados }\end{array}$ \\
\hline tcpRtoMin & $\begin{array}{l}\text { valor mínimo permitido para o "time-out" de retransmissão TCP, em } \\
\text { milissegundos }\end{array}$ \\
\hline tcpRtoMax & $\begin{array}{l}\text { valor máximo permitido para o "time-out" de retransmissão TCP, em } \\
\text { milissegundos }\end{array}$ \\
\hline tcpMaxConn & $\begin{array}{l}\text { limite de conexões que podem ser abertas pela entidade de } \\
\text { transporte do dispositivo }\end{array}$ \\
\hline tcpCurrEstab & número de conexões de transporte corretamente abertas \\
\hline
\end{tabular}

Tabela 3.13 - Objetos para Gerenciamento de Configuração (TCP)

- o objeto tcpRtoAlgorithm permite a configuração do algoritmo de retransmissão de octetos TCP não confirmados. A configuração inadequada pode resultar em congestionamento na rede ou distribuição injusta de banda passante. Consultando-se freqüentemente os objetos tcpRtoMin, tcpRtoMax e 


\section{Proposta de Arquitetura de Gerência para a RedUnB usando a Plataforma Tivoli TME 10}

tcpRtoAlgorithm pode-se verificar se a configuração está adequada ao ambiente de seu sistema de rede.

- o objeto tcpMaxConn ajuda a configurar a rede para suportar o número de conexões TCP remotas necessárias. Este número pode ser calculado observandose o objeto tcpCurrEstab que informa o número de conexões TCP estabelecidas no momento.

\section{Objetos para Gerenciamento de Performance}

\begin{tabular}{|l|l|}
\hline Objeto & Informação usada para gerenciamento de Performance \\
\hline tcpAttempt Fails & numero de tentativas de conexão falhadas \\
\hline tcp EstsabResets & numero de reinicializacões de conexões estabelecidas \\
\hline tcpRetransSegs & numero de segmentos retransmitidos \\
\hline tcpInErrs & numero de pacotes recebidos com erro \\
\hline tcpOutRsts & numero de vezes que a entidade tentou reinicializar uma conexão \\
\hline tcpInSegs & taxa de segmentos TCP recebidos \\
\hline tcpOutSegs & taxa de segmentos TCP enviados \\
\hline
\end{tabular}

Tabela 3.14 - Objetos para Gerenciamento de Performance (TCP)

- pela observação do objeto tcpAttemptFails pode-se medir a confiabilidade da rede, onde um número menor de falhas indicam uma rede mais confiável.

- pela observação do objeto tcpEstabResets também pode-se medir a confiabilidade da rede, sendo que, quanto maior o número de conexões estabelecidas reinicializadas, menos confiável é a rede.

- o objeto tcpRetransSegs informa o número de segmentos TCP que o sistema está retransmitindo, esta informação pode indicar se uma entidade está tendo que fazer várias retransmissões para garantir a confiabilidade.

- o objeto tcpInErrs indica o número de segmentos recebidos com erro. O aumento deste objeto pode ser causado pelo encapsulamento incorreto dos segmentos pelo sistema de origem, alguma rede repassando os segmentos com erro, ou outras razões. 


\section{Proposta de Arquitetura de Gerência para a RedUnB usando a Plataforma Tivoli TME 10}

- o objeto tcpOutRsts informa o número de vezes que a entidade tentou reinicializar uma conexão..

- os objetos tcpInSegs e tcpOutSegs permitem a checagem da taxa de segmentos TCP que entram e saem da entidade.

\section{Objetos para Gerenciamento de Contabilização}

\begin{tabular}{|l|l|}
\hline Objeto & Informação usada para gerenciamento de Contabilização \\
\hline tcpActiveOpens & numero de vezes que o sistema abriu uma conexão \\
\hline tcpPassiveOpens & numero de vezes que o sistema recebeu um pedido de abertura de conexão \\
\hline tcpInSegs & numero total de segmentos TCP recebidos \\
\hline tcpOutSegs & numero total de segmentos TCP emitidos \\
\hline tcpConnTable & tabela das conexões TCP correntes \\
\hline
\end{tabular}

Tabela 3.15 - Objetos para Gerenciamento de Contabilização (TCP)

- os objetos tcpActiveOpens e tcpPassiveOpens informa o número total de vezes em que uma conexão foi feita de, ou para um sistema, respectivamente.

- os objetos tcpInSegs e tcpOutSegs juntos contam os segmentos TCP que entram e saem da entidade, respectivamente.

- o objeto tcpConnTable é uma tabela com as atuais conexões TCP, e contém os seguintes campos:

○ tcpConnState: estado da conexão

- tcpConnLocalAddress: endereço TCP local

- tcpConnLocalPort: endereço IP local

- tcpConnRemAddress: endereço TCP remoto

- tcpConnRemPort: endereço IP remoto

O campo tcpConRemAddress determina o endereço do sistema remoto que está conectado à entidade. A consulta freqüente a este campo permite o conhecimento de quais sistemas usam os recursos da rede e durante quanto tempo.

Muitas aplicações TCP usam portas bem definidas, tornando possível determinar-se quais aplicações estão fazendo ou recebendo conexões TCP. 


\section{Proposta de Arquitetura de Gerência para a RedUnB usando a Plataforma Tivoli TME 10}

\section{Objetos para Gerenciamento de Segurança}

As informações da tabela tcpConnTable também podem ser usados para gerenciamento de segurança, pois permite o conhecimento dos sistemas que acessam recursos via TCP. O tempo de polling influenciará grandemente na eficiência do gerenciamento, pois um intruso pode levar apenas alguns segundos para pegar as informações que deseja e fechar a conexão. Se nenhum poll for feito neste intervalo, o intruso não será detectado.

\subsection{8 - O Grupo UDP}

O UDP é um protocolo de transporte que, ao contrário do TCP, não garante segurança e nem estabelece conexões, ao invés disso ele usa um fluxo de datagramas para transportar as informações. $\mathrm{O}$ grupo UDP possui um número limitado de objetos. $\mathrm{O}$ grupo TCP pode ajudar no gerenciamento de performance, de contabilização, e de configuração.

Este grupo é subdividido em dois grupos:

1. objetos gerais sobre o UDP nesta entidade

2. entradas sobre as aplicações UDP, que estão recebendo datagramas correntemente, na entidade em questão

\section{Objetos para Gerenciamento de Performance}

\begin{tabular}{|l|l|}
\hline Objeto & Informação usada para gerenciamento de Performance \\
\hline udpInDatagrams & taxa de datagramas recebidos \\
\hline udpOutDatagrams & taxa de datagramas enviados \\
\hline UdpNoPorts & taxa de datagramas que não foram enviados para uma porta valida \\
\hline UdpInErrors & taxa de datagramas UDP recebidos com erro \\
\hline
\end{tabular}

Tabela 3.16 - Objetos para Gerenciamento de Performance (UDP)

- a consulta periódica aos objetos udpInDatagrams e udpOutDatagrams pode determinar a taxa de entrada e saída de datagramas. 


\section{Proposta de Arquitetura de Gerência para a RedUnB usando a Plataforma Tivoli TME 10}

- o objeto udpNoPorts informa quando a entidade está recebendo datagramas de uma aplicação inválida. Uma taxa alta desses datagramas pode resultar em problemas de performance.

\section{Objetos para Gerenciamento de Contabilização}

\begin{tabular}{|l|l|}
\hline Objeto & Informação usada para gerenciamento de Performance \\
\hline udpInDatagrams & numero total de datagramas UDP recebidos \\
\hline udpOutDatagrams & numero total de datagramas UDP enviados \\
\hline UdpTable & portas UDP recebendo datagramas correntemente \\
\hline
\end{tabular}

Tabela 3.17 - Objetos para Gerenciamento de Contabilização (UDP)

- os objetos udpInDatagrams e udpOutDatagrams determinam quantos datagramas UDP foram recebidos e enviados pela entidade.

- o objeto udpTable é composto pelos seguintes campos:

○ udpLocalAddress: endereço IP local

○ udpLocalPort: porta UDP local

Como o UDP não é um protocolo baseado em conexão, as entradas da tabela acima são válidas somente para o período em que a aplicação escuta uma porta.

Objetos para Gerenciamento de Configuração:

Checando o objeto udpTable, pode-se determinar se as aplicações da entidade estão setadas corretamente. Por exemplo, se é conhecido que uma entidade tem uma aplicação que oferece impressão remota em uma determinada porta, esta configuração pode ser facilmente verificada usando o objeto udpTable.

\section{Objetos para Gerenciamento de Segurança}

O objeto udpTable também pode ser usado para gerenciamento de segurança. Pode-se checar este objeto para assegurar que uma entidade não executou uma determinada aplicação. Por exemplo, se determinarmos que uma determinada aplicação escuta requisições por uma porta UDP específica. A ferramenta de gerenciamento pode 


\section{Proposta de Arquitetura de Gerência para a RedUnB usando a Plataforma Tivoli TME 10}

checar o objeto udpTable de todos os sistemas para verificar se esta porta UDP local está sendo escutada.

\subsection{9 - O Grupo EGP}

O EGP é um protocolo que informa a um dispositivo de rede IP como alcançar outras redes IP. Ele não informa a rota completa para a outra rede, mas ela permite que um dispositivo saiba em que direção que a rede existe. Redes IP podem ser agrupadas em áreas lógicas chamadas sistemas autônomos. Um sistema autônomo geralmente é uma rede e suas subredes associadas ou uma coleção de redes e subredes sob uma mesma administração. Dois dispositivos de rede em dois sistemas autônomos distintos podem compartilhar informações de alcançabilidade via EGP.

Os dispositivos de rede que comunicam com o EGP entre sistemas autônomos são chamados vizinhos EGP. Cada processo EGP tem uma relação um-para-um com cada vizinho. Cada vizinho EGP conversa um protocolo hello que periodicamente informa outros vizinhos que ele ainda está ativo. Quando o sistema consulta a informação de alcançabilidade do vizinho, ele está fazendo um EGP poll.

Os objetos do grupo EGP são subdivididos em dois grupos:

1. informações sobre o EGP nesta entidade.

2. uma tabela de entradas contendo informações sobre cada vizinho EGP.

Os objetos do grupo EGP podem ser aplicados ao gerenciamento de falhas, de configurações, de performance e de contabilização.

\section{Objetos para Gerenciamento de Falhas}

\begin{tabular}{|l|l|}
\hline Objeto & Informação usada para gerenciamento de Falhas \\
\hline EgpNeighState & estado de cada vizinho EGP \\
\hline egpNeighStateUps & número de vezes que um vizinho EGP entrou no estado UP \\
\hline egpNeighStateDows & número de vezes que um vizinho EGP entrou no estado DOWN \\
\hline
\end{tabular}

Tabela 3.18 - Objetos para Gerenciamento de Falhas (EGP) 


\section{Proposta de Arquitetura de Gerência para a RedUnB usando a Plataforma Tivoli TME 10}

Os objetos listados acima estão contidos na tabela de vizinhos EGP (objeto egpNeighTable).

O estado de um vizinho EGP pode prover informações de como a informação de roteamento é injetada no sistema autônomo. A aplicação de gerenciamento de falhas pode usar o objeto egpNeighState para conhecer o estado atual de um vizinho EGP. Se o vizinho EGP está no estado up, então ele deverá estar enviando informações sobre alcançabilidade de redes ao processo EGP local.

Sabendo-se quando um vizinho entra no estado up pode sinalizar sobre novas informações de roteamento que devem entrar no sistema autônomo. Já saber quando o vizinho pára a comunicação, e entra no estado down pode ser útil na resolução de problemas de roteamento.

\section{Objetos para Gerenciamento de Configuração}

\begin{tabular}{|l|l|}
\hline Objeto & Informação usada para gerenciamento de Configuração \\
\hline egpNeighState & estado de cada vizinho EGP \\
\hline egpNeighAddr & endereço IP do vizinho EGP \\
\hline EgpNeighAs & sistema autônomo do vizinho EGP \\
\hline egpNeighIntervalHello & intervalo entre retransmissões de comandos Hello \\
\hline egpNeighIntervalPoll & intervalo entre retransmissões de comandos Poll \\
\hline egpNighMode & modo de polling desta entidade EGP \\
\hline egpNeighEventTrigger & permite iniciar ou finalizar uma comunicação \\
\hline EgpAs & sistema autônomo local \\
\hline
\end{tabular}

Tabela 3.19 - Objetos para Gerenciamento de Configuração (EGP)

- o objeto egpAs informa o número do sistema autônomo da entidade EGP local.

- os demais objetos estão contidos no objeto egpNeighTable e dizem respeito à configuração de um vizinho específico .

- o objeto egpNeighEventTrigger pode ser usado para iniciar e encerrar uma comunicação com um vizinho EGP (já existente). Este objeto permite o controle 


\section{Proposta de Arquitetura de Gerência para a RedUnB usando a Plataforma Tivoli TME 10}

do processo EGP do sistema. Este é o único objeto do grupo EGP que pode ser setado pelo engenheiro de rede através de um comando SNMP Set-Request.

\section{Objetos para Gerenciamento de Performance}

\begin{tabular}{|l|l|}
\hline Objeto & Informação usada para gerenciamento de Performance \\
\hline EgpInMsgs & taxa de mensagens recebidas \\
\hline EgpInErrors & taxa de mensagens recebidas com erro \\
\hline EgpOutMsgs & taxa de mensagens enviadas \\
\hline egpOutErrors & taxa de mensagens não enviadas devido a ocorrência de erros \\
\hline egpNeighInMsgs & taxa de mensagens recebidas deste vizinho EGP \\
\hline egpNeighInErrs & taxa de mensagens recebidas com erro deste vizinho EGP \\
\hline egpNeighOutMsgs & taxa de mensagens enviadas a este vizinho EGP \\
\hline egpNeighOutErrs & taxa de mensagens não enviadas a este vizinho EGP devido a erros \\
\hline egpNeighInErrMsgs & taxa de mensagens de erro recebidas deste vizinho EGP \\
\hline egpNeighOutErrMsg & taxa de mensagens de erro enviadas a este vizinho EGP \\
\hline
\end{tabular}

Tabela 3.20 - Objetos para Gerenciamento de Performance (EGP)

- os objetos egpInMessages e egpOutMessages permitem calcular a taxa de mensagens EGP que entram e saem da entidade. Geralmente esta taxa será insignificante, mas em alguns momentos de instabilidade da rede entre os vizinhos EGP, essa taxa pode aumentar e influenciar na performance da entidade.

- o aumento do valor dos objetos egpInErrors e egpOutErrors geralmente coincide com o aumento do número de mensagens recebidas e enviadas pela entidade. Se uma mensagem é recebida com erro e uma resposta válida não é enviada, o vizinho EGP originador deverá retransmitir a mensagem. Quando a entidade não pode enviar mensagens EGP válidas devido a limitações de recursos, o valor do objeto egpOutErros irá aumentar. Consequentemente, quando a taxa de egpInMessages aproxima-se da taxa de egpOutErrors, a 


\section{Proposta de Arquitetura de Gerência para a RedUnB usando a Plataforma Tivoli TME 10}

entidade provavelmente estará tendo dificuldades em construir e enviar mensagens EGP.

- da mesma forma usando os objetos egpNeighInMsgs, egpNeighInErrs, egpNeighOutMsgs e egpNeighOutErrs permite o cálculo da taxa de entrada e saída de mensagens e erros de cada vizinho.

\subsubsection{0 - O Grupo CMOT}

O Grupo CMOT existe somente por razões históricas. O CMOT é um protocolo que ajuda na transição do SNMP para o CMIS/CMIP. No entanto, embora a definição para o CMOT exista, nenhum trabalho significativo tem sido feito em cima deste protocolo desde algum tempo, e logo não há nenhum objeto neste grupo.

\subsubsection{1 - O Grupo Transmission}

O Grupo transmission provê informações sobre o meio específico que forma a base das interfaces no sistema. Quando os padrões Internet para gerenciar vários tipos de meios forem definidos, este grupo será o prefixo para estas informações.

\subsubsection{2 - O Grupo SNMP}

Os objetos do grupo SNMP podem ser aplicados em todas as cinco áreas de gerenciamento. Aplicações de gerenciamento de falhas observando só problemas SNMP podem achar útil conhecer o número de erros SNMP e sua freqüência, enquanto aplicações de gerenciamento de performance podem calcular a taxa de pacotes SNMP entrando e deixando a entidade. Já aplicações de gerenciamento de contabilização podem usar os objetos SNMP para encontrar o número de pacotes SNMP enviados ou recebidos pela entidade. E por fim, alguns objetos do grupo SNMP podem ajudar no gerenciamento de configuração e segurança. 


\section{Proposta de Arquitetura de Gerência para a RedUnB usando a Plataforma Tivoli TME 10}

\section{Objetos para Gerenciamento de Falhas}

\begin{tabular}{|l|l|}
\hline Objeto & Informação usada para gerenciamento de Falhas \\
\hline snmpInASNParseErrs & total de mensagens recebidas com erros ASN \\
\hline snmpInTooBigs & total de mensagens recebidas com erro "too big" \\
\hline snmpInNoSuchNames & total de mensagens recebidas com erro "SuchName" \\
\hline snmpInBadValues & total de mensagens recebidas com erro "badValue" \\
\hline snmpInReadOnlys & total de mensagens recebidas com erro "readOnly" \\
\hline snmpInGenErrs & total de mensagens recebidas com erro "genErr" \\
\hline snmpOutTooBigs & total de mensagens enviadas com erro "too big" \\
\hline snmpOutNoSuchNames & total de mensagens enviadas com erro "noSuchName" \\
\hline snmpOutBadValues & total de mensagens enviadas com erro "badValue" \\
\hline snmpOutGenErrs & total de mensagens enviadas com erro "genErr" \\
\hline
\end{tabular}

Tabela 3.21 - Objetos para Gerenciamento de Falhas (SNMP)

Os objetos listados na tabela 3.21 informam erros referentes a mensagens SNMP. Esses erros não indicam erros na rede em si, mas pode informar que a entidade não está manipulando os pacotes SNMP apropriadamente. O número e tipos de erros também podem indicar que a entidade está recebendo pacotes SNMP com erros dos dispositivos da rede. A solução para esses erros geralmente está na configuração do gerente ou agente SNMP. Se a reconfiguração não diminuir o número de erros, o problema provavelmente residirá na implementação do gerente ou agente SNMP. 


\section{Proposta de Arquitetura de Gerência para a RedUnB usando a Plataforma Tivoli TME 10}

\section{Objetos para Gerenciamento de Performance}

\begin{tabular}{|l|l|}
\hline Objeto & Informação usada para gerenciamento de Falhas \\
\hline SnmpInPkts & taxa de pacotes SNMP recebidos \\
\hline SnmpOutPkts & taxa de pacotes SNMP enviados \\
\hline snmpInTotalReqVars & taxa de Get/Get-Next-Requests recebidas \\
\hline snmpInTotalSetVars & taxa de Set-Requests recebidas \\
\hline snmpInGetRequests & taxa de Get-Requests recebidas \\
\hline SnmpInGetNexts & taxa de Get-Next-Requests recebidas \\
\hline snmpInSetRequests & taxa de Set-Requests recebidas \\
\hline snmpInGetResponses & taxa de Get-Responses recebidas \\
\hline SnmpInTraps & taxa de Traps recebidas \\
\hline snmpOutGetRequests & taxa de Get-Requests enviadas \\
\hline snmpOutGetNexts & taxa de Get-Next-Requests enviadas \\
\hline snmpOutSetRequests & taxa de Set-Requests enviadas \\
\hline snmpOutGetResponses & taxa de Get-Responses enviadas \\
\hline SnmpOutTraps & taxa de Traps enviadas \\
\hline
\end{tabular}

Tabela 3.22 - Objetos para Gerenciamento de Performance (SNMP)

Como qualquer outra atividade da entidade, o SNMP pode afetar a performance do sistema. Se deseja-se conhecer a porcentagem de recursos de uma entidade está usando para manipular o SNMP, pode-se calcular a taxa de pacotes SNMP recebidos ou enviados, usando os objetos snmpInPkts e snmpOutPkts.

Os demais objetos listados na tabela acima permite que se conheça os tipos de pacotes SNMP que a entidade está manipulando. 


\section{Proposta de Arquitetura de Gerência para a RedUnB usando a Plataforma Tivoli TME 10}

\section{Objetos para Gerenciamento de Contabilização}

\begin{tabular}{|l|l|}
\hline Objeto & Informação usada para gerenciamento de Contabilização \\
\hline SnmpInPkts & taxa de pacotes SNMP recebidos \\
\hline SnmpOutPkts & taxa de pacotes SNMP enviados \\
\hline SnmpInTraps & taxa de traps recebidas \\
\hline SnmpOutTraps & taxa de traps enviadas \\
\hline
\end{tabular}

Tabela 3.23 - Objetos para Gerenciamento de Contabilização (SNMP)

Os objetos snmpInPkts, snmpOutPkts, snmpInTraps, e snmpOutTraps permitem calcular o total de pacotes e traps recebidos e enviados. Estas informações podem ser úteis no gerenciamento de contabilização.

\section{Objetos para Gerenciamento de Segurança}

\begin{tabular}{|c|c|}
\hline Objeto & Informação usada para gerenciamento de Segurança \\
\hline snmpInBadCommunityNames & total de pacotes com uma community string incorreta \\
\hline snmpInBadCommunityUses & $\begin{array}{l}\text { total de pacotes com community string que não permite a } \\
\text { operação requisitada }\end{array}$ \\
\hline
\end{tabular}

Tabela 3.24 - Objetos para Gerenciamento de Segurança (SNMP)

- o objeto snmpInBadCommunityNames conta o número de vezes que um usuário ou aplicação, na tentativa de comunicar-se com o SNMP de uma entidade, não informou a community string correta.

- o objeto snmpInBadCommunityUses conta o número de vezes que um pacote SNMP é recebido contendo uma community string que não permite a operação requisitada. 


\section{Proposta de Arquitetura de Gerência para a RedUnB usando a Plataforma Tivoli TME 10}

\section{Objetos para Gerenciamento de Configuração}

\begin{tabular}{|l|l|}
\hline Objeto & Informação usada para gerenciamento de Configuração \\
\hline snmpEnableAuthenTraps & indica se o agente SNMP pode enviar traps \\
\hline
\end{tabular}

Tabela 3.25 - Objetos para Gerenciamento de Configuração (SNMP)

\section{9 - Comparação entre a MIB da OSI e a MIB da Internet}

As MIB's da ISO e da Internet são modeladas através de técnicas de programação por objeto. Dentro deste contexto, os recursos a serem gerenciados são representados através de objetos gerenciados.

A diferença entre estas duas MIB's reside nas hierarquias usadas para representar os objetos. Na MIB da ISO são definidas três hierarquias: hierarquia de herança, hierarquia de nomeação e hierarquia de registro.

A hierarquia de herança ou de classes está relacionada às propriedades associadas a um determinado objeto. Dentro desta hierarquia diz-se que objetos da mesma classe possuem propriedades similares.

No caso da Internet não são usados os conceitos de classes de objetos e seus respectivos atributos. São definidos tipos de objetos. A definição de tipos de objetos contém cinco campos: nome textual com o respectivo identificador de objeto (OBJECT IDENTIFIER), uma sintaxe ASN.1, uma descrição do objeto, o tipo de acesso e o status.

A hierarquia de nomeação ou de containment é usada para identificar instâncias de objetos. Este tipo de hierarquia não é definido no caso da Internet.

Finalmente tem-se a hierarquia de registro que é especificada em ambos padrões.

\subsection{0 - Remote Procedure Call - RPC}

RPC é uma chamada remota de procedimentos (Remote Procedure Call), que fornece um mecanismo para um host fazer uma chamada de procedimento que aparentemente faz parte do processo local mas é realmente executada em outra máquina 


\section{Proposta de Arquitetura de Gerência para a RedUnB usando a Plataforma Tivoli TME 10}

da rede. O host no qual é executada a chamada do procedimento tem recursos que não estão disponíveis na máquina que a chamou.

\subsection{1 - Modelo Cliente / Servidor}

A distribuição de serviços computacionais impõe uma relação cliente/servidor entre os dois hosts, o host que possui um recurso é o servidor para aquele recurso, o host que chama um recurso se torna cliente do servidor que o possui.

\subsection{2 - Mecanismo}

Muitos mecanismos cliente/servidor podem ser definidos para cada máquina na rede. Um servidor para um recurso é seguidamente um cliente de muitos outros na mesma rede.

\subsection{3 - Funcionamento do RPC}

\subsubsection{1 - Argumentos do procedimento}

O sistema RPC envia os argumentos passados ao procedimento através de um datagrama de rede.

\subsubsection{2 - Comunicação}

O cliente RPC cria uma sessão ao localizar o servidor apropriado, e envia um datagrama ao processo no servidor que pode executar o RPC. No servidor, os argumentos são desempacotados; é executado o procedimento, o resultado é empacotado (se existir), e enviado de volta ao cliente. De volta ao cliente, a resposta é convertida em um valor de retorno para a chamada de procedimento, e a aplicação de usuário é recomeçada como se um procedimento local tivesse terminado. Esse é o fim de "sessão" como definido no modelo ISO. 


\section{Proposta de Arquitetura de Gerência para a RedUnB usando a Plataforma Tivoli TME 10}

\subsubsection{3 - Transporte}

O transporte é efetuado pelos protocolos TCP e UDP. Serviços RPC podem ser construídos tanto em transportes TCP ou UDP. A maioria dos serviços são orientados a UDP porque eles estão baseados em requerimentos de curta-duração. Usando UDP força que a chamada de RPC contenha suficiente informação de contexto para sua execução independente de qualquer outro requerimento de RPC, já que os pacotes UDP podem chegar em qualquer ordem.

\subsubsection{4 - Timeout}

Quando uma chamada de RPC é realizada, o cliente deve especificar um período de timeout no qual a chamada deve se realizar. Se o servidor estiver sobrecarregado ou desligado, a chamada remota não será executada antes do fim do timeout. A ação tomada no timeout do RPC varia de aplicação para aplicação. Algumas mandam de volta a chamada de RPC, enquanto outras procuram outro servidor.

\subsection{4 - Identificando Serviços RPC}

Serviços disponíveis através de RPC são identificados através de quatro valores:

- Número de Programa

- Número da Versão

- Número do Procedimento

- Protocolo (UDP ou TCP)

O número de programa unicamente identifica o serviço RPC

O serviço em si (identificado com um único número de programa) pode ser composto por vários procedimentos. O número de procedimento é passado num requerimento RPC como um opcode ao servidor RPC. Números de procedimento 


\section{Proposta de Arquitetura de Gerência para a RedUnB usando a Plataforma Tivoli TME 10}

começam em 1 (0 é a função null). Enquanto os números de programa são bem divulgados, os números de procedimento são particulares ao serviço. Seguidamente, os números de procedimento estão contidos num arquivo de cabeçalho (header) que é compilado dentro do programa cliente. Por exemplo, os números de procedimento de NFS (Network Filesystem) estão definidos no arquivo de cabeçalho /usr/include/nfs/nfs.h

\subsubsection{1 - RPC Portmapper}

O serviço portmap existe para registrar serviços RPC e fornecer seus números de porta IP quando dado um certo número de programa RPC. O próprio portmapper é ele mesmo um serviço RPC, com uma porta IP bem conhecida (111) para poder ser contatada diretamente pelos hosts remotos. O portmapper é também utilizado para tratar o RPC Broadcast, um requerimento que é enviado para todos os servidores para um serviço RPC particular.

\subsubsection{2 - Números de versão RPC}

Cada nova implementação de um servidor RPC tem seu próprio número de versão. Números diferentes são usados para coordenar múltiplas implementações do mesmo serviço, cada um dos quais podem ter interfaces diferentes. À medida que um serviço RPC amadurece, o autor do serviço pode achar necessário adicionar novos procedimentos ou novos argumentos para procedimentos existentes. Modificando a interface implica em incrementar o número de versão. A primeira versão de um programa RPC é 1. Quando contactando o portmapper num host remoto, tanto o lado local como o lado remoto devem se entender quanto ao número de versão para o serviço RPC que será usado. A regra básica é a de usar o número de versão mais alto que os dois lados conseguem entender. 


\section{4 - Software Tivoli}

\section{1 - Tivoli Management Environment 10 (TME 10)}

O Tivoli Management Environment 10 (TME 10) é um ambiente de gerenciamento de sistemas distribuídos. Os principais módulos são apresentados nos itens seguintes:

\subsection{1 - Tivoli TME 10 Estrutura do Produto}

A Figura 4.1 a seguir ilustra a estrutura do Tivoli TME.

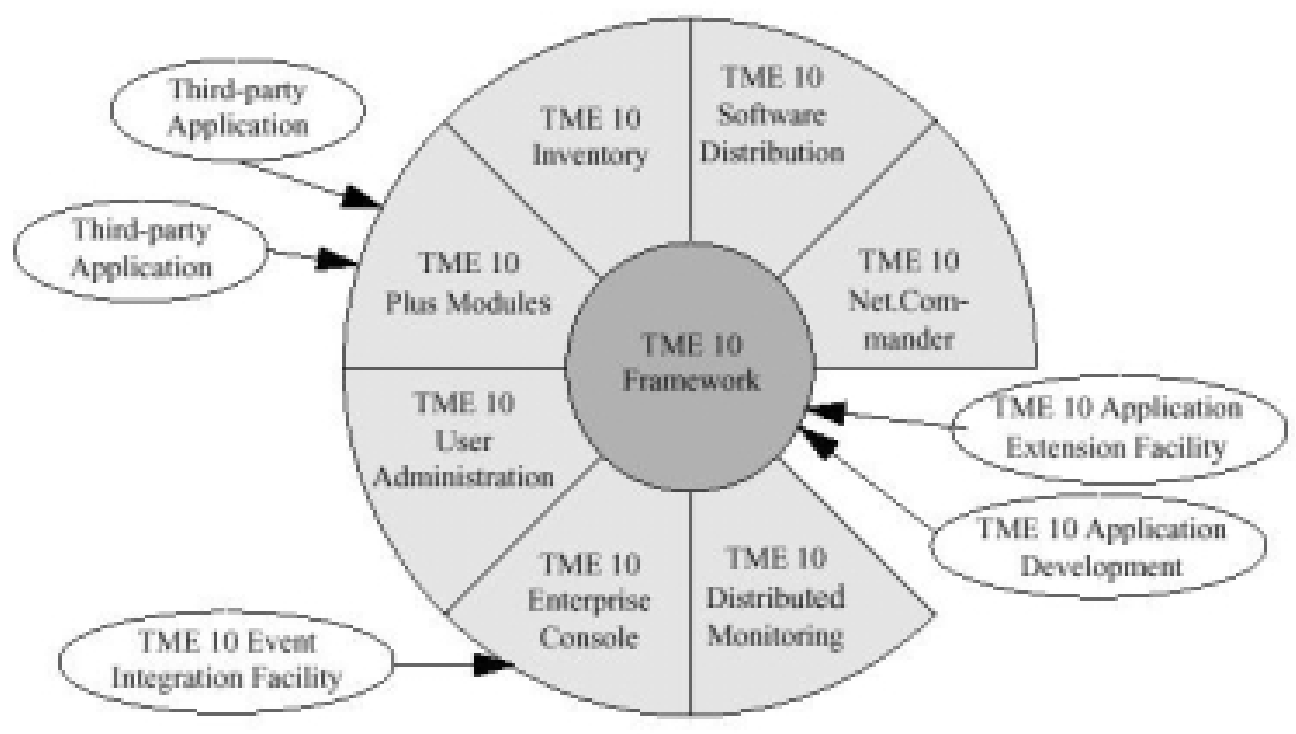

Figura 4.1 - Estrutura do Tivoli TME

Antes de maiores explicações sobre o TME é preciso lembrar que o TME Framework é um produto distinto das outras aplicações do TME; é possível adquiri-lo e instalá-lo separadamente para qualquer aplicação de gerencia, tanto para o Tivoli como para soluções do tipo third party.

No TME 10, algumas facilidades como instalação, o desktop de gerência do Tivoli, os subsistemas de notificação, e as regiões (policy regions) são partes do Framework, particularmente uma das aplicações do Tivoli. Quando o Framework é instalado pode-se ver a interface gráfica completa que é composta dos seguintes ícones;

- Managed node icons

- Policy regions

- Notification bulletin board 


\section{Proposta de Arquitetura de Gerência para a RedUnB usando a Plataforma Tivoli TME 10}

- Administrator definitions

- Policy and task libraries

- Scheduler

\subsection{2 - Tivoli Management Environment 10 Framework}

Tivoli Management Environment 10 (TME 10) Framework é o componente básico da linha de produtos TME 10, produz capacidades de administração de sistemas básicos, bem como serviços fundamentais para aplicações de gerenciamento. Estas capacidades de serviços incluem facilidades na administração do Tivoli, facilidades no policiamento de sistemas e facilidades nas notificações. Com arquitetura de gerenciamento orientada a objetos que possibilita a operação de um ambiente multiplataforma. Interface única entre os módulos de gerenciamento, adere a padrões abertos permitindo a integração com várias ferramentas de terceiros. Implementa em suas aplicações as estruturas de Policy Region e Profile Manager. A primeira consiste em estruturas hierárquicas criadas para organizar os recursos gerenciados; a segunda, em perfis de gerência, são utilizados por aplicações básicas da solução Tivoli para executar tarefas. Os perfis são compostos de informações relativas a cada aplicação. Por exemplo, perfis da aplicação Tivoli Distributed Monitoring vão conter informações como o que deve ser monitorado num determinado grupo de servidores, e que a ação deve ser tomada quando os limites pré-estabelecidos forem alcançados.

Gerenciadores de Perfis são grupos de profiles, os quais são aplicados a endpoints, que em última instância serão os servidores ou estações alvo das aplicações.

O TME 10 Famework permite instalar e criar vários serviços de gerência que possibilitam ao mesmo gerenciar recursos em sua rede. $\mathrm{O}$ usuário pode instalar qualquer serviço dependendo de suas necessidades. Somente o TMR server pode ser instalado. A seguir é mostrado uma lista de serviços de gerência proporcionados pelo TME 10 Framework, e a descrição de cada um. 


\section{Proposta de Arquitetura de Gerência para a RedUnB usando a Plataforma Tivoli TME 10}

\section{- TMR server (TMR-S)}

O TMR-S inclue as livrarias, binários, data files, e a interface gráfica do usuário (GUI) é necessário para instalar e gerenciar seu ambiente do TME 10. TMR servers mantém o banco de dados do TMR server e coordena todas as comunicações com o TME 10 managed nodes. O servidor também presume toda autenticação e verificação necessária para prover a segurança ao banco de dados do TME 10.

\section{- Managed node}

O TME 10 managed node roda o mesmo software que o TMR server. Managed nodes mantém seus próprios bancos de dados, cada um pode ser acessado pelo TMR server. Quando um managed node se comunica com outro managed node, essa comunicação ou operação de segurança é feita da mesma forma que é feita pelo TMR server. A diferença primordial entre TMR server e managed node é o tamanho do banco de dados.

\section{- Endpoint gateway}

Um endpoint gateway controla todas as comunicações e operações nos TME 10 endpoints. Um simples gateway pode suportar comunicação com milhares de endpoints. O gateway pode inicializar aplicações nos endpoints ou por eles.

Um gateway é criado em um managed node já existente. Esse managed node responsável prove acesso as aplicações nos endpoints e também comunicação com o TMR server que ocasionalmente os endpoints requisitam.

\section{- Endpoints}

O endpoint é qualquer sistema que roda um serviço endpoint (ou daemon) tipicamente, um endpoint é instalado em uma máquina que não usa diariamente operações de gerência. $\mathrm{O}$ endpoint roda um pequeno número de softwares e não tem um 


\section{Proposta de Arquitetura de Gerência para a RedUnB usando a Plataforma Tivoli TME 10}

banco de dados específico a essa aplicação. A maioria dos sistemas nas instalações do TME 10 são endpoints. O TME GUI não é instalado nos endpoints. Se for escolhido rodar o desktop em um endpoint, o TME 10 Desktop terá que ser instalado.

\section{- PC managed node and PC agent}

O PC managed node é um PC rodando o software agente. O software agent tem que ser instalado e tem que ser criado um PC managed node se tiver aplicações do TME 10 que não estão ainda habilitadas para o uso com endpoints.

\subsubsection{1 - Componentes do TME 10 Framework}

Temos a seguir os componentes da linha de produtos TME 10 e a relação destes produtos entre si de forma hierárquica:

- O TME 10 Framework, baseado em um sistema industrial padrão, constituído de capacidades básicas de sistemas de administração assim como um grupo de serviços fundamentais para aplicações de gerencia. Essas capacidades e serviços incluem instrumentos de administração, instrumentos que fornecem privilégios administrativos, além de sistemas responsáveis por definir a política e instrumentos de notificação.

- O TME Desktop proporciona uma interface gráfica com o usuário (GUI) assim como uma interface do tipo linha de comando (CLI).

- O TME 10 possui também ferramentas para realizar gerenciamento em tipos específicos de sistemas e serviços, incluindo, entre outros, aplicações de auditoria e distribuição de softwares, monitoramento remoto, gerenciamento de usuários e gerencia de internet e intranet.

As demais facilidades do TME 10 serão apenas citadas para que o leitor possa ter uma visão mais clara do esquema apresentado abaixo: 
- TME 10 AEF (Application Extension Facility) que permite que o TME 10 customize dinâmicamente as aplicações suportadas pelo TME.

- TME 10 EIF (Event Integration Facility) permite que construção de adaptadores de eventos para mapear eventos de qualquer aplicação, recurso ou componente em um formato compatível com o TME 10 Enterprise Console.

- TME 10 ADE (Application Development Environment) onde estão incluídas as ferramentas de programação para a criação de novos aplicativos de gerenciamento que funcionarão a partir do Framework.

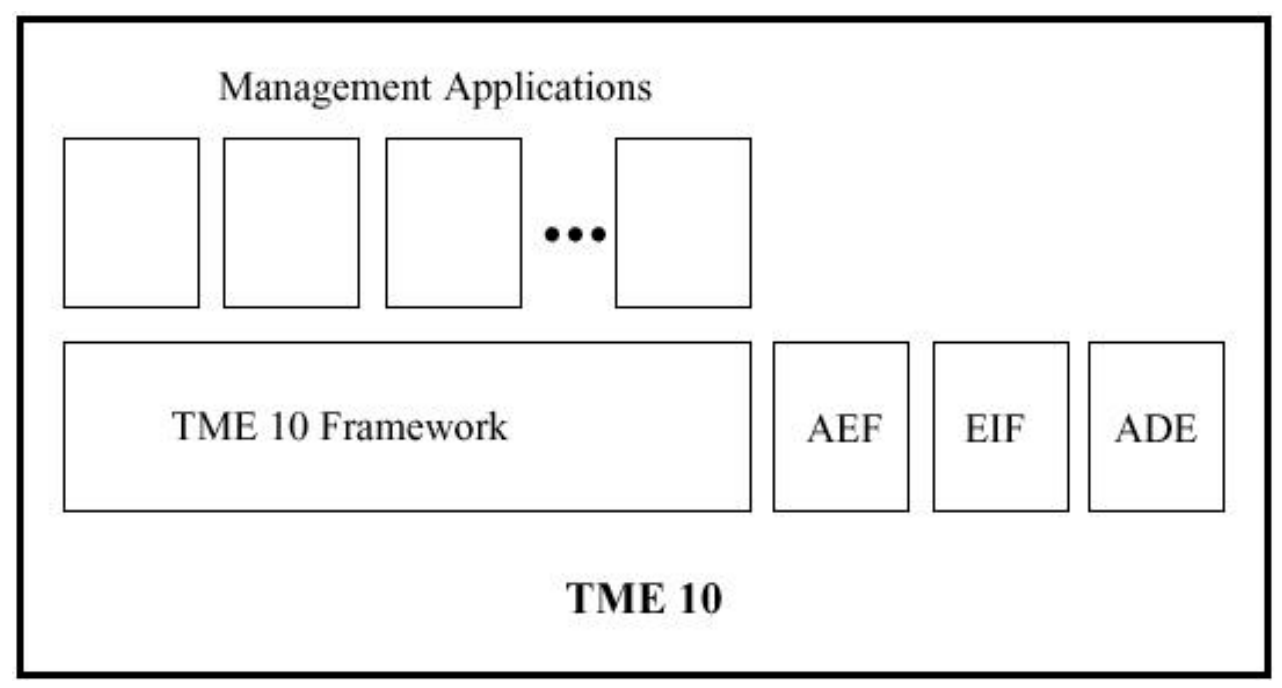

Figura 4.2 - Relação dos produtos da linha TME 10 entre si de forma hierárquica

\section{2 - O Gateway e o Cliente Endpoint}

O Gateway e o Cliente Endpoint permitem a instalação do TME 10 como sendo uma solução do tipo third party como mostra a figura 4.3. 


\section{Proposta de Arquitetura de Gerência para a RedUnB usando a Plataforma Tivoli TME 10}

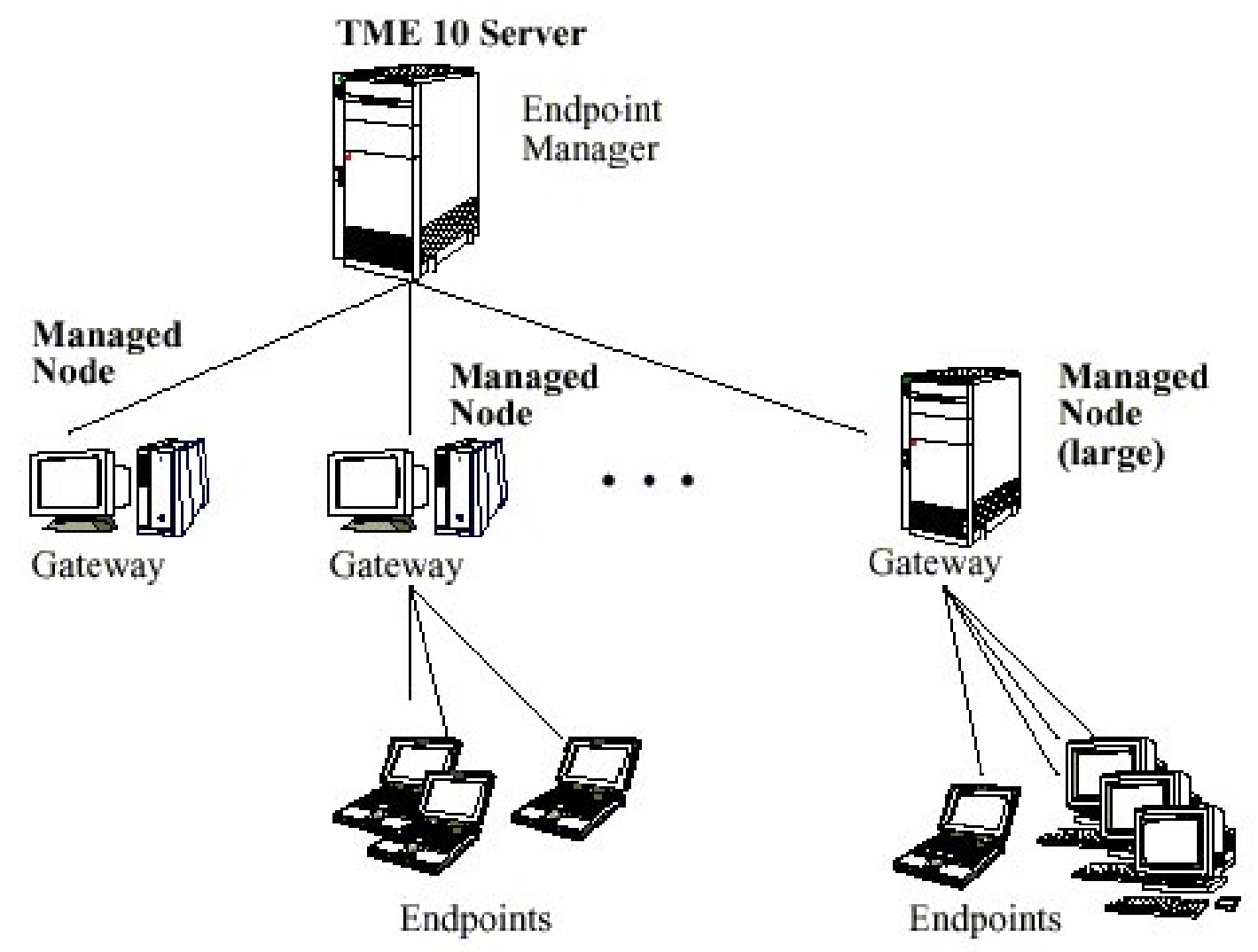

Figura 4.3 - Gateway e o Cliente Endpoint

Com um número reduzido de nós a serem gerenciados a quantidade de comunicação entre os nós e o TMR-S é diminuída de forma significativa. Os endpoints não se comunicam com o TMR-S a não ser durante o processo inicial de login. Todas as comunicações dos endpoints são passadas ao Gateway. Na maioria dos casos o Gateway proporciona todo o suporte que um endpoint necessita sem que seja necessário haver comunicação com o TMR-S.

Em redes pequenas é possível que o Gateway seja criado no próprio TMR-S. O TMR-S é capaz de lidar com toda a comunicação requerida quando se trata de uma rede com poucas máquinas.

Mas isso não é aceitável quando se trata de redes de grande porte; o TMR-S, nesse caso, ficaria sobrecarregado. 


\section{Proposta de Arquitetura de Gerência para a RedUnB usando a Plataforma Tivoli TME 10}

\section{3 - Disciplinas do Tivoli}

São softwares que têm funções distintas entre si , que são instalados e rodam a partir do TME 10.

As disciplinas encontradas no Tivoli TME são apresentadas a seguir para que se possa ter uma visão melhor do propósito de cada uma delas.

\subsection{1 - Disciplinas de Monitoramento da Rede}

Englobam o acompanhamento da performance da rede sobre os protocolos mais usuais, levantamento dos equipamentos ligados à rede (auto-discovery), elaboração da topologia e gerência de eventos com notificações de problemas. Podendo ser classificadas como parte das modalidades de gerência de falhas e performance (Netview).

\subsection{2 - Disciplinas de Segurança}

São os aplicativos que permitem a aplicação de políticas de segurança, como: proteção de vírus com atualização automatizada, autenticação e controle de acesso à rede e recursos unificados e realização de cópias de segurança em resposta a eventos que indiquem comprometimento dos serviços em execução, confundindo-se com a modalidade de gerência de segurança (Tivoli Security Management).

\subsection{3 - Disciplina de Inventário}

Compreende a manutenção de base de dados contendo os dispositivos identificados na rede. No caso de computadores, esta disciplina prevê a catalogação dos recursos disponíveis (memória, disco, periféricos, etc.), bem como da lista de aplicativos instalados (Tivoli Inventory). 


\section{Proposta de Arquitetura de Gerência para a RedUnB usando a Plataforma Tivoli TME 10}

\subsection{4 - Disciplina de Distribuição de Software}

Funciona em conjunto com a disciplina de inventário, ao distribuir a todas ou a um grupo de máquinas da rede (que obedecem a um critério de classificação, como as que têm sistema operacional Unix, por exemplo) pacotes de aplicativos. Esta distribuição pode tomar duas formas: a primeira sendo a execução de instalação não acompanhada do software, em que um agente apropriado responde às indagações do programa instalador; e a segunda sendo a cópia de um pacote já instalado, com seus arquivos acessórios e alterações no sistema operacional (Tivoli Software Distribution).

\subsection{5 - Disciplina de Servidores e Clientes}

Esta disciplina prevê a monitoração e controle de servidores com funções específicas, como autenticadores de contas, correios eletrônicos, bancos de dados e outros. Em alguns casos é referenciada como disciplina de groupware (conjunto de aplicativos para uso em grupos de colaboração).

Além disso a disciplina de servidores e clientes engloba a gerência de estações clientes, monitorando protocolos de rede instalados, serviços em execução e outros parâmetros de interesse; está sob a modalidade de configuração.

\subsection{6 - Disciplina de Help Desk}

Destacam-se, nesta disciplina, os aplicativos voltados ao controle remoto de estações, acompanhamento de ordens de serviço, e a manutenção de bases de dados com os problemas e soluções mais comuns para um dado ambiente. Estes dados podem ser, a título de ilustração, disponibilizados em uma interface internet para consulta dos usuários, buscando a melhoria dos conhecimentos da massa usuária de serviços de informática, e por conseqüência deixando mais tempo aos técnicos para planejamento de ações preventivas. 


\section{Proposta de Arquitetura de Gerência para a RedUnB usando a Plataforma Tivoli TME 10}

\subsection{7 - Disciplina de Internet;}

A priori, está disciplina está contida na disciplina de servidores e clientes, entretanto, como o acesso e aplicações voltadas à internet estão cada vez mais presentes nas corporações, já se faz necessário um acompanhamento diferenciado, tal como: monitorar a performance do servidor $W E B$ e implementar eficiente segurança contra ataques externos.

\section{4 - Definições Específicas}

\subsection{1 - TME 10 desktop}

É uma interface de usuário que provê acesso rápido á apresentação e componentes do TME 10.

\subsection{2 - Remote Control}

É uma disciplina do TME 10 que permite ao administrador do sistema controlar o teclado e o mouse, além da saída do monitor de um sistema remoto rodando diversas plataformas, tais como, Windows NT, Windows 95/98, Windows 3.x ou OS/2. O administrador pode monitorar o PC e permitir ao usuário manter o controle de seu sistema, mas também permite ao gerente assumir o controle total da máquina a ser gerenciada com ou sem a autorização do usuário, podendo modificar configurações, instalar e remover programas, além de apagar arquivos e diretórios. Os procedimentos de instalação do agente serão apresentados com detalhes mais adiante neste relatório.TME 10 Remote Control pode ser usado até mesmo para reiniciar um PC remotamente dando grande flexibilidade de gerenciamento.

Essas funcionalidades permitem: uma melhora no suporte de primeiro nível, diminuição da necessidade de envio de técnicos para dar suporte local, assegura diagnósticos mais rápidos e precisos e redução no tempo de duração das chamadas do help-desk. 


\section{Proposta de Arquitetura de Gerência para a RedUnB usando a Plataforma Tivoli TME 10}

\subsection{3 - NetView}

O NetView é uma ferramenta de gerenciamento de sistema e de rede que proporciona funções de configuração, falha e desempenho. Possui uma plataforma de gerenciamento de rede aberto que habilita a integração de aplicações SNMP (Simple Network Management Protocol) e CMIP(Common Management Information Protocol). Permite ao usuário descobrir redes TCP/IP, mapear topologia, receber eventos e traps SNMP e monitorar performance. Além disto, é possível inserir produtos dos mais variados fabricantes de equipamentos de infra-estrutura de redes do mercado, visualizando graficamente estes equipamentos e sendo possível configurá-los através do Tivoli NetView.

O módulo NetView executa o discovery da rede através de pings sucessivos enviados para redes pré-definidas através da configuração de comunidades, e tem como principais características:

- Gerenciamento do ambiente TCP/IP;

- Gerenciamento de sistemas UNIX;

- Gerenciamento de problemas e inventário;

- Gerenciamento de clientes e servidores IPX e NetBIOS;

- Gerenciamento de redes SNA;

- Gerenciamento de hubs IBM;

- Gerenciamento de redes distribuídas e heterogêneas utilizando protocolos de gerenciamento baseados em TCP/IP;

- Distribuição de tarefas de gerenciamento pela rede, reduzindo o tempo de processamento, o tráfego broadcast da rede;

- Gerencia todos os dispositivos IP que possuam agente SNMP;

- Possui interface gráfica padrão OSF/Motif e Xwindow System; 


\section{Proposta de Arquitetura de Gerência para a RedUnB usando a Plataforma Tivoli TME 10}

- Customização da inteface gráfica de acordo com a necessidade do usuário;

- Software possui um conjunto de objetos MIB já instalados. Outros podem ser acrescidos;

- Possui APIs (Application User Interface) que proporciona aplicações sem necessidade de conhecer os detalhes de implementação:

- End-User Interface (EUI) API

- X/Open Management Protocols (XMP) API

- SNMP API

$\circ \quad$ Event Filtering API

- Process Management API

- Network Logging and Tracing API

- General Topology (GTM) API

Por definição, o NetView armazena os dados em arquivos internos. Contudo, ele pode ser configurado para trabalhar com banco de dados relacionais comerciais. $\mathrm{O}$ NetView recebe os dados da estação de trabalho que está gerenciando. Os dados são armazenados no site do servidor de banco de dados, o qual é executado nas diferentes estações onde o NetView se encontra. Estes dados podem ser acessados e compartilhados por qualquer estação que tenha o run-time e a configuração correta do banco de dados.

\subsection{4 - Distributed Monitoring}

Outra disciplina do software Tivoli usada neste trabalho é o Distributed Monitoring onde o status de uma variedade de recursos da rede, tais como, sistemas, aplicações e processos são verificados, tal aplicação é usada para monitorar recursos locais ou remotos e apresentar eventos e alarmes da rede. Disponibiliza uma monitoração distribuída dos recursos de sistemas remotos, proporcionando a integração 


\section{Proposta de Arquitetura de Gerência para a RedUnB usando a Plataforma Tivoli TME 10}

destes ao ambiente corporativo, dando uma visão centralizada de toda a estrutura. Este produto implementa um grande número de monitores que verificam a "saúde" dos vários tipos de servidores de um ambiente distribuído. É possível monitorar desde a quantidade de espaço livre em disco, porcentagem de utilização de CPU, até quantidade de swap de páginas em memória.

Os componentes utilizados pelo Distributed Monitoring são o TME 10 DM profiles, o TME 10 DM engine e Indicator collections.

\subsection{5 - Software Distribuiton}

Finalmente será apresentada a disciplina do software Tivoli Software Distribuiton que permite a distribuição e instalação automática de softwares em máquinas de uma rede heterogênea de forma eficiente. O software é distribuído a partir de um repositório central para os servidores intermediários (fanout servery), e destes para as estações alvo, que estarão sempre sincronizadas umas com as outras. O produto ainda oferece características como a elaboração automática de pacotes, determinação da utilização de banda e agenda para o processo de distribuição. Tem total integração com o módulo de inventário, sendo possível pesquisar os pré-requisitos de hardware e software das máquinas alvo da distribuição. 
Proposta de Arquitetura de Gerência para a RedUnB usando a Plataforma Tivoli TME 10

\section{5- Metodologia, Resultados e Análise}

\section{1 - TME 10 Framework}

A descrição deste experimento é iniciada pela base do Tivoli TME 10, o TME Framework, como já foi descrito anteriormente na parte que trata do Tivoli TME 10 Estrutura do Produto (item 4.1.1 deste relatório).

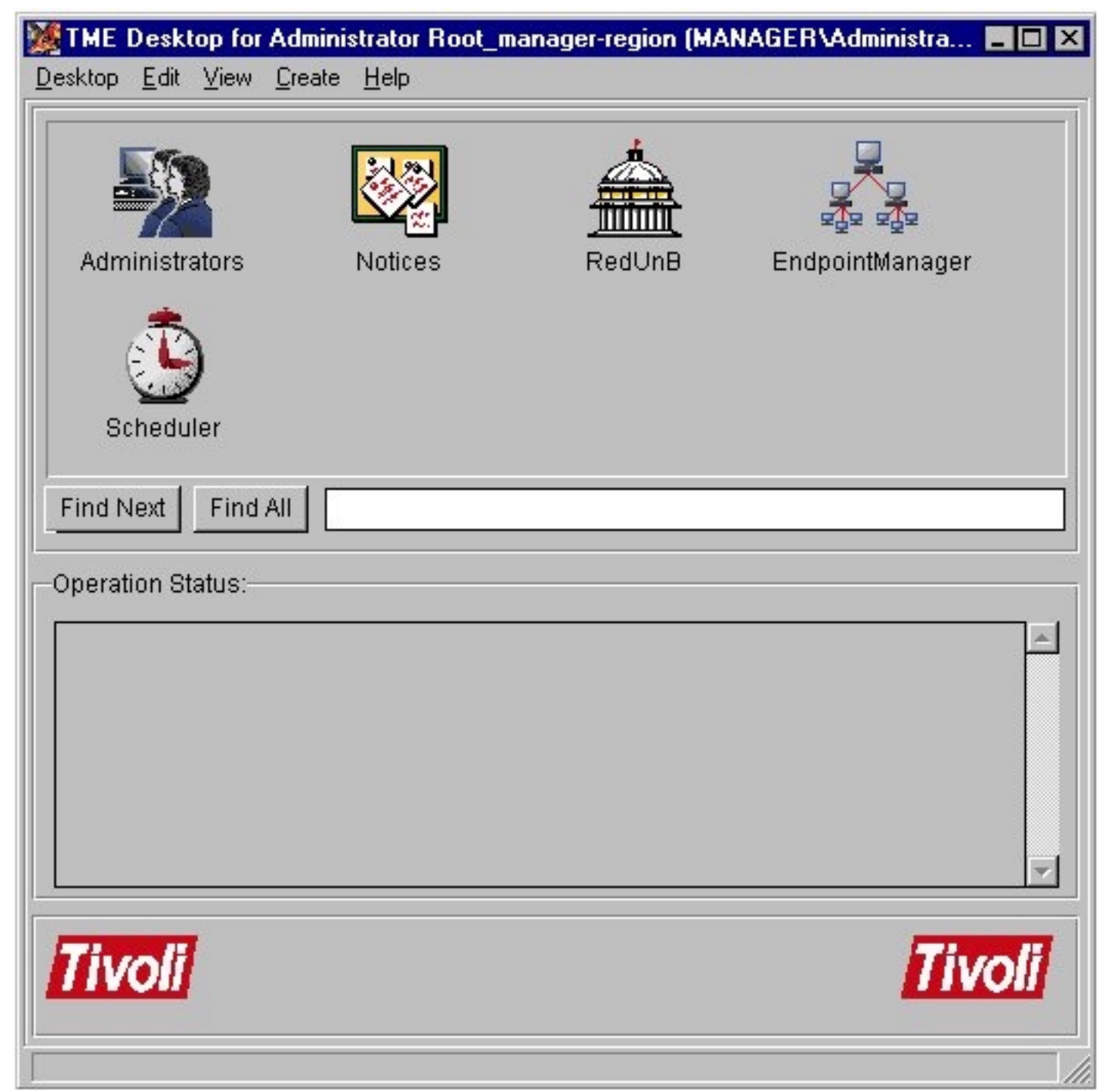

Na figura 5.1 é apresentada a interface gráfica do software:

Figura 5.1 - Interface gráfica do Software Tivoli 


\section{Proposta de Arquitetura de Gerência para a RedUnB usando a Plataforma Tivoli TME 10}

A instalação do Tivoli Framework é bastante simplificada e pode ser realizada acompanhando as instruções do capítulo 6 do Manual do Framework (TME 10 Framework Planning and Installation Guide, localizado no CD do Framework no arquivo MPG2.PDF), algumas informações consideradas relevantes ao processo de instalação serão apresentadas a seguir.

O TMR-S e os seus clientes devem possuir seus próprios daemons oserv (objetos de envio que permanecem sempre ativos). O daemon oserv do TMR-S coordena as comunicações entre ele e os clientes. Cada oserv dentro dos clientes deve utilizar a mesma porta que o TMR-S; é necessário instalar o Framework no TMR-S antes de se instalar qualquer cliente do TME 10 ou qualquer uma das suas aplicações.

Antes da instalação do TME 10 são necessários alguns procedimentos, destacando-se os seguintes: os nomes dos nós gerenciados pelo TME 10 devem ser incluídos no DNS.

Se estiver sendo utilizado o DHCP nos clientes utilizando Windows NT deve-se assegurar que o TMR-S também deverá ser uma máquina rodando Windows NT;

Se na sua rede houve clientes Windows NT é necessário que seja instalado o Tivoli Remote Execution System em pelo menos um dos sistemas NT, se o TMR-S for Windows NT este serviço é instalado automaticamente;

Se estiver no planejamento compartilhar os binários na rede é preciso, para o Windows NT, que se crie uma conta de acesso remoto.

O Tivoli Remote Execution Service (TRIP) instala clientes do Windows NT remotamente, o TRIP monitora serviços do tipo exec na porta 512; ele deve ser instalado localmente em cada cliente NT. O primeiro sistema NT localizado pelo Framework que contém o TRIP instalado será designado como o repetidor NT.

\section{2 - NetView}

No que se refere ao experimento de gerência de falhas, desempenho e configuração da rede foi utilizado o software Tivoli NetView. A instalação desta disciplina foi feita na máquina gerente. O Netview, como foi explicado anteriormente, 
Proposta de Arquitetura de Gerência para a RedUnB usando a Plataforma Tivoli TME 10

mapeou a RedUnB e a rede do ENE. A figura 5.2 apresenta a topologia lógica mapeada pelo software, que será explicada mais a frente:

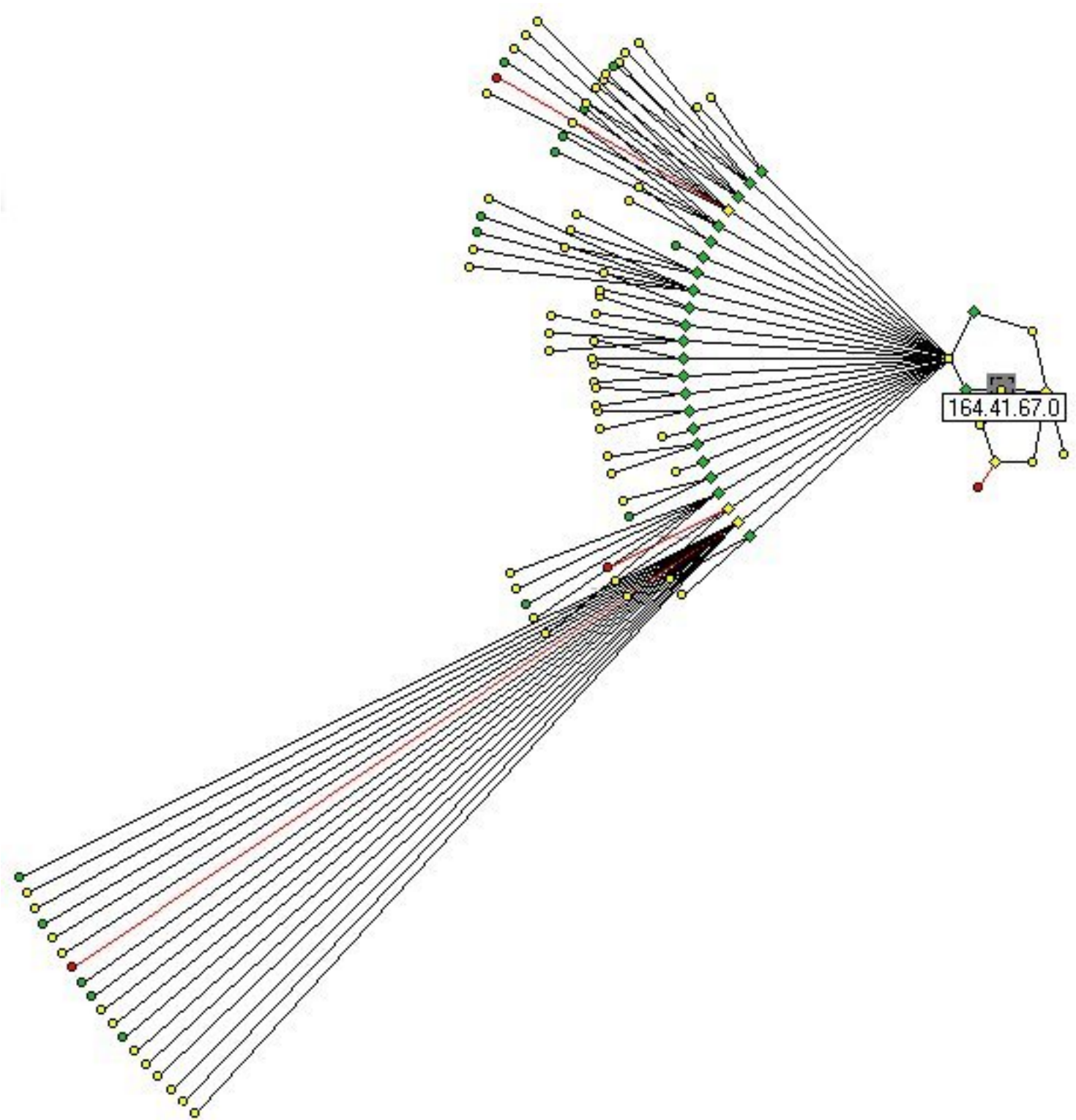

Figura 5.2 -Mapeamento da RedUnB e rede ENE pelo software NetView

Após ter se instalado e configurado o Framework pode-se instalar o Tivoli NetView para que se inicie o descobrimento (Discovery) e o monitoramento (Monitoring) da rede; novamente apenas as informações consideradas relevantes serão apresentadas. O método completo de instalação pode ser acompanhado a partir do CD de instalação do NetView (arquivo readme.html). 


\section{Proposta de Arquitetura de Gerência para a RedUnB usando a Plataforma Tivoli TME 10}

Antes de se instalar o NetView alguns requisitos de software devem ser observados, são eles: sistema operacional Windows NT versão 4, protocolo TCP/IP instalado e configurado, e serviço SNMP instalado e configurado; se for necessário instalar o kit sem que o SNMP esteja rodando é preciso usar o flag -ss com o setup. Apesar de existir esta possibilidade é altamente recomendado que a instalação seja realizada com o serviço SNMP rodando, senão é preciso ter um arquivo de origem para realizar o autodiscovery da rede. Opcionalmente pode-se instalar o Microsoft SQL versão 6.5 .

Partiu-se para a instalação do NetView seguindo as instruções contidas no manual, após a instalação e configuração, o NetView funcionou com perfeição começando a realizar o autodiscovery da rede.

A parte mais importante da instalação do NetView é a configuração das communities, deliberadas pelos gerentes das redes locais, que definem níveis de autoridade dos mesmos, permitindo que os equipamentos possam ser gerenciados. No caso de não terem sido configuradas todas as communities da rede a ser gerenciada nesta primeira configuração, é possível acrescentar outras a partir da interface gráfica do NetView.

É importante preservar tais communities pois com elas um invasor pode facilmente modificar configurações em equipamentos fundamentais para $o$ funcionamento da rede podendo modificar inclusive o endereço IP de roteadores e switches.

Com o autodiscovery acionado e com as communities configuradas em pouco tempo é possível se ter uma idéia bastante clara da topologia lógica da rede que está sendo gerenciada.

A interface gráfica do NetView permite visualmente que o gerente da rede fique a par das condições de funcionamento da rede através do código de cores utilizado pelo software, onde vermelho significa estado critico, ou seja, máquina desligada ou ainda uma rede fora do ar; amarelo, que significa que algum nó está com problemas naquela rede, podendo ser apenas um computador pessoal desligado. Existe a possibilidade de se escolher que nós gerenciar e que nós ignorar, uma política a esse respeito é fundamental para que, ao ser gerado um alarme de falha, moderada ou crítica, o gerente saiba 


\section{Proposta de Arquitetura de Gerência para a RedUnB usando a Plataforma Tivoli TME 10}

exatamente onde tal falha ocorreu e qual a sua relevância para o funcionamento geral da rede; e finalmente a cor verde que significa funcionamento normal do equipamento. Tal conceito de ferramenta facilita muito o gerente da rede no que se refere à gerência de falhas.

Outra grande utilidade do NetView é a ferramenta Event Browser, de onde se pode selecionar que tipos de evento se deseja observar, a partir desta ferramenta pode-se ter uma visão mais específica dos problemas ocorridos na rede.

Finalmente citamos a ferramenta mais importante do NetView, segundo a concepção dos realizadores deste projeto, que é a ferramenta MIB Browser a partir da qual pode-se realizar as tarefas de gerência de falhas, desempenho e configuração, cujas explicações são apresentadas pelas tabelas da parte de MIB do relatório (item 3.8).

O pacote Netview pode fazer a coleta e modificar MIB's de todos os equipamentos mapeados e que tem um agente SNMP instalado e configurado. A modificação das MIB's é uma ferramenta poderosa, tendo em vista que a MIB, como foi explicado anteriormente compreende as informações e as configurações da máquina.

Para melhorar o nível de gerência e para visualizar mais a fundo o funcionamento dos softwares do Tivoli, foi instalado o software Sniffer Pro (item 5.4). Como já era esperado, foi observado que o NetView usa o protocolo SNMP para realizar as aplicações como captura e modificação de MIB's, bem como outras aplicações (ver figura 5.3 ). 


\section{Proposta de Arquitetura de Gerência para a RedUnB usando a Plataforma Tivoli TME 10}

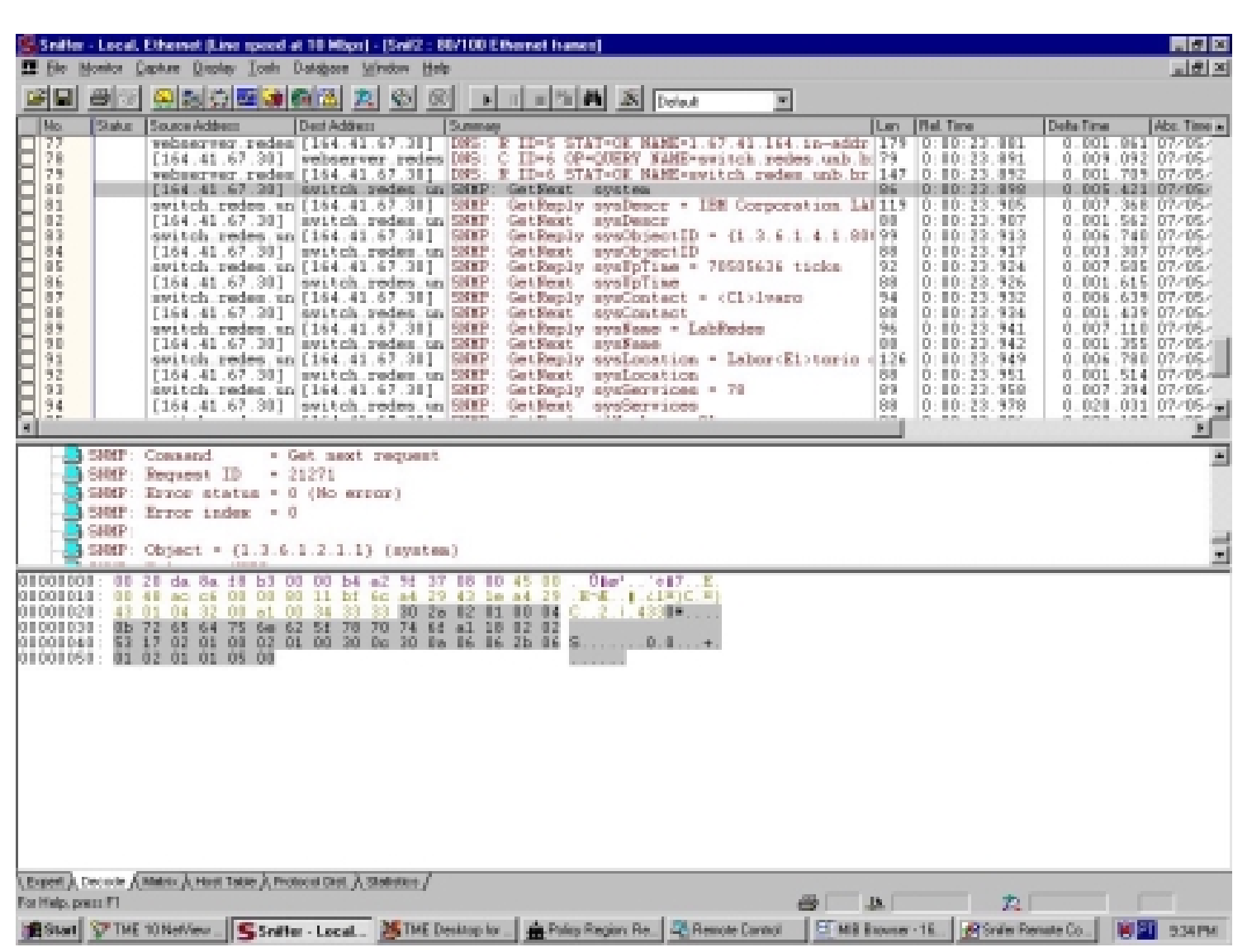

Figura 5.3 - Visualização com sniffer da utilização do protocolo SNMP pelo Netview

O experimento do módulo NetView mapeou as redes do backbone da RedUnB e do backbone do ENE indicando uma quantidade de nós superior a 1700 entre HUBS, SWITCHES e placas de rede chegando ao nível de computadores pessoais. Testes realizados, como coleta de MIB's, troca de valores de MIB's e monitoração da rede foram executados com êxito, tornando este e outros softwares de gerência modelo de demonstrações a pessoas interessadas no assunto.

\section{3 - Remote Control}

A experiência com a disciplina Remote Control foi feita instalando-se agentes Tivoli em algumas máquinas de fácil acesso, localizadas no Laboratório de Redes da UnB, e que não estavam sendo utilizadas. Para que esta disciplina do Tivoli seja disponibilizada é necessário que se crie um PcManage Node (ver figura 5.4 a seguir) no Tivoli desktop do TMR-S, em seguida deve-se criar um ícone de Remote Control. 


\section{Proposta de Arquitetura de Gerência para a RedUnB usando a Plataforma Tivoli TME 10}

Ao se clicar no ícone Remote Control, se escolhe a máquina em que se quer realizar esta operação (ver figura 5.5). O agente do Remote Control precisa ser instalado na máquina cliente pelo gerente por meio do software Tivoli Desktop, na opção Install Products. Os testes foram realizados de todas as formas disponibilizadas pelo software (ver figura 5.6), como monitor/monitor que permite a monitoração da máquina pelo gerente, control/active que permite controle total da máquina pelo gerente, control/monitor, que permite ao usuário escolher se deseja ser controlado ou só monitorado e o Reboot, que, como o próprio nome diz, reinicializa a máquina (ver figura 5.7). Existem algumas opções de tempo de espera pela resposta do cliente (ver figura 5.8); as mesmas foram testadas, é bom ser citado que a escolha do tempo de espera de 0 segundos possibilita ao gerente monitorar, assumir o controle ou reinicializar a máquina sem a necessidade da permissão do usuário. $\mathrm{O}$ fato do usuário não estar presente para dar permissão ao gerente não impede que o gerente não execute a tarefa desejada, pelo fato de existir uma opção Proceed if time out, que responde ao comando se o tempo de resposta estipulado pelo gerente espirar. Outras opções são apresentadas na tela.

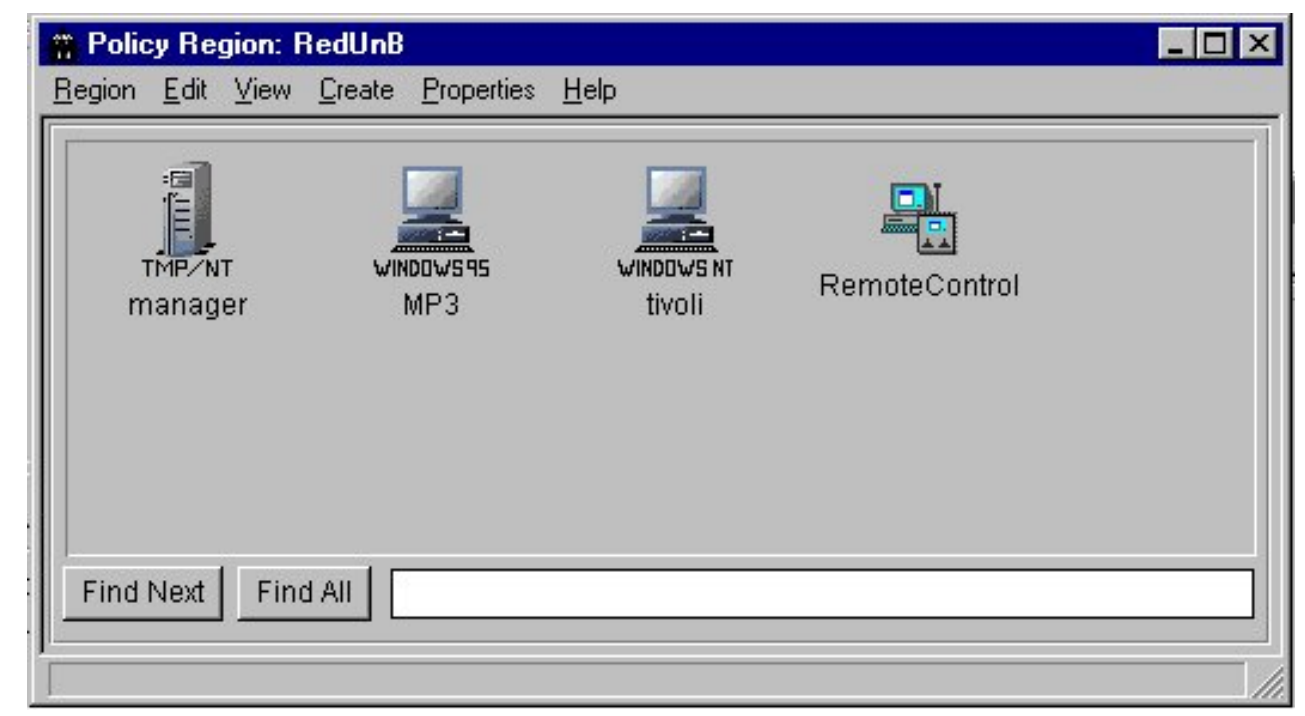

Figura 5.4 - Policy Region: RedUnB 
Proposta de Arquitetura de Gerência para a RedUnB usando a Plataforma Tivoli TME 10

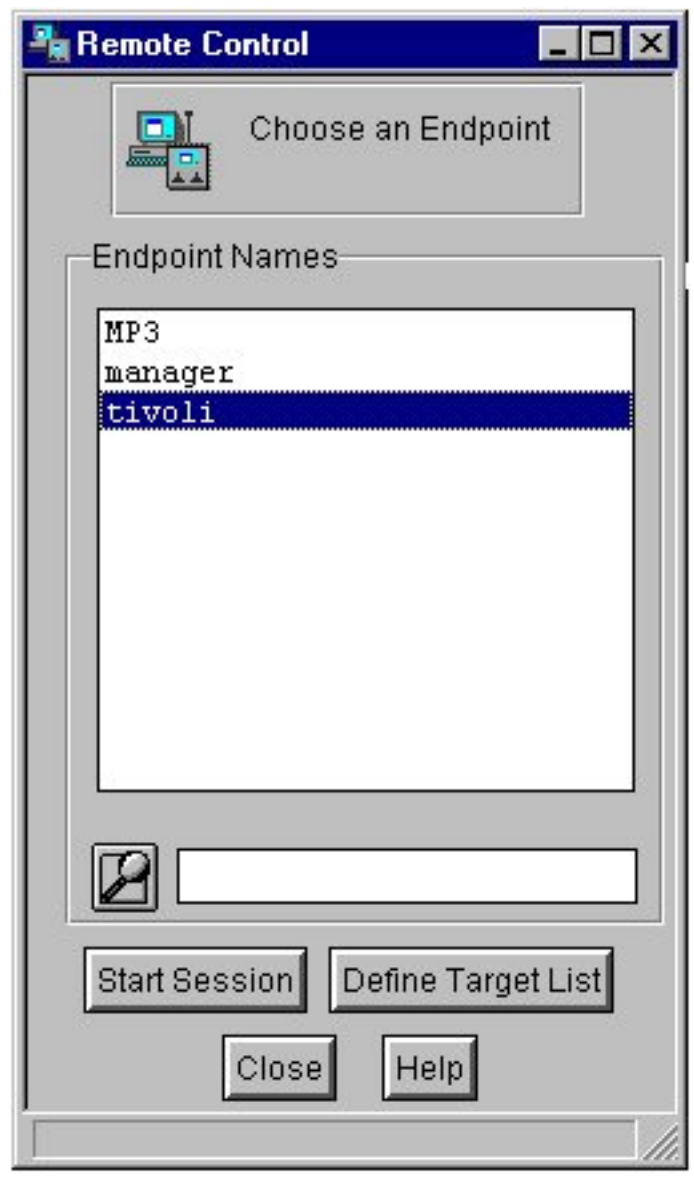

Figura 5.5 - Remote Control

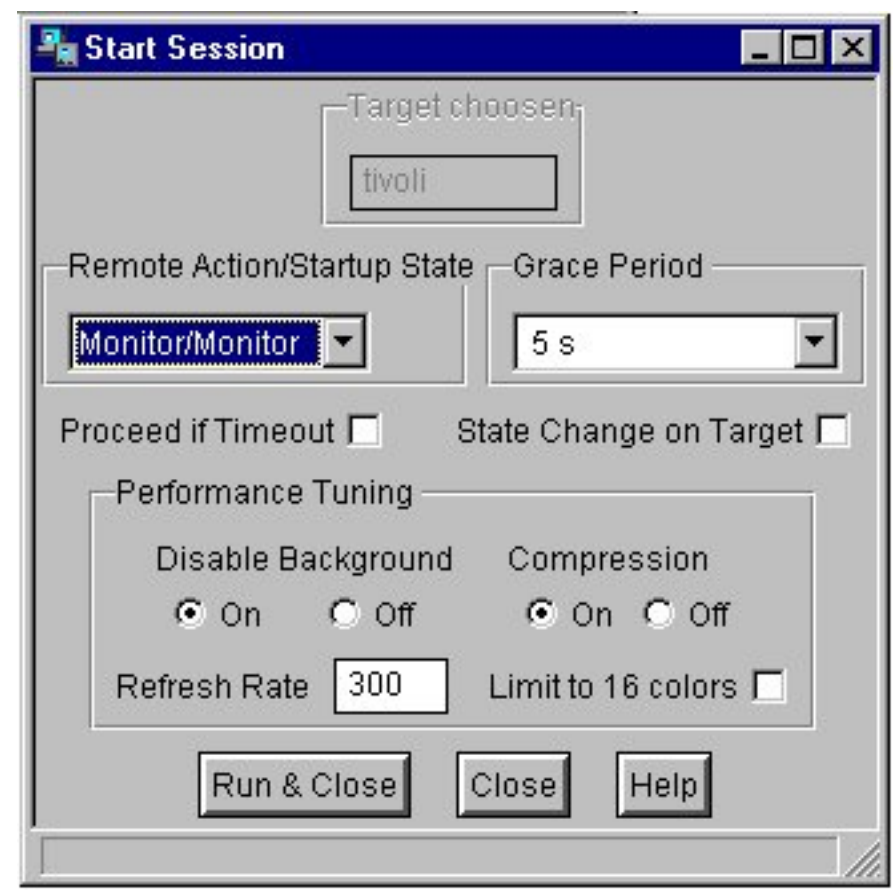

Figura 5.6 - Remote Control Options 


\section{Proposta de Arquitetura de Gerência para a RedUnB usando a Plataforma Tivoli TME 10}

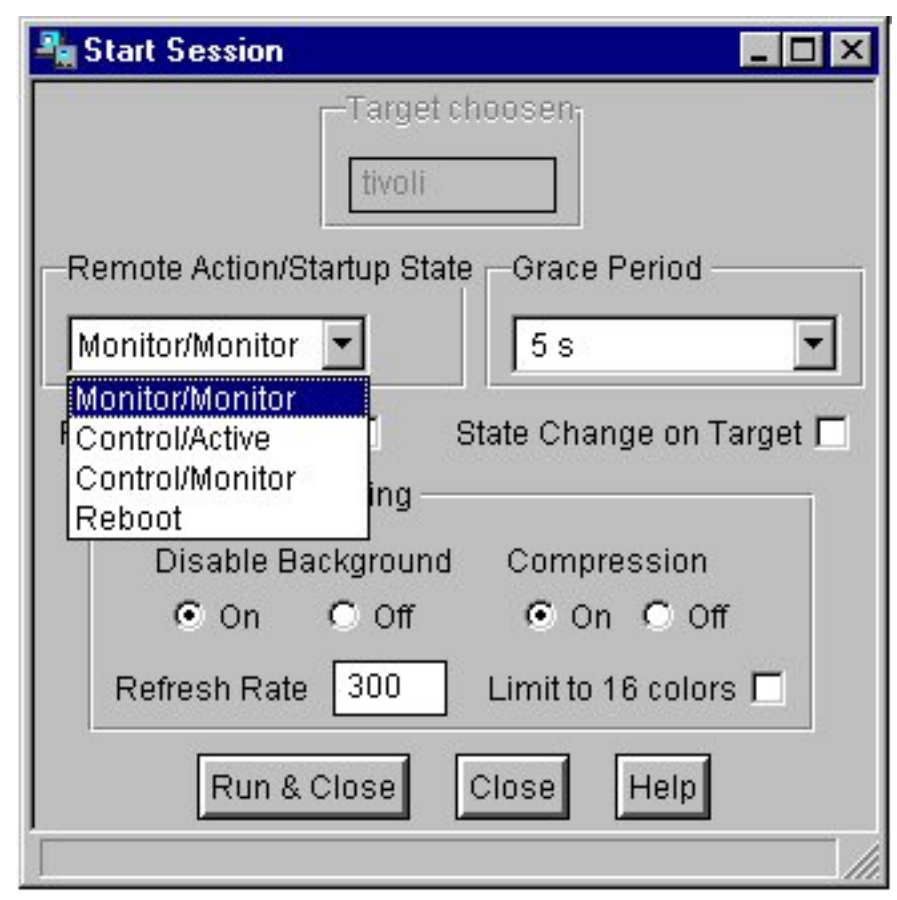

Figura 5.7 - Remote Control action options

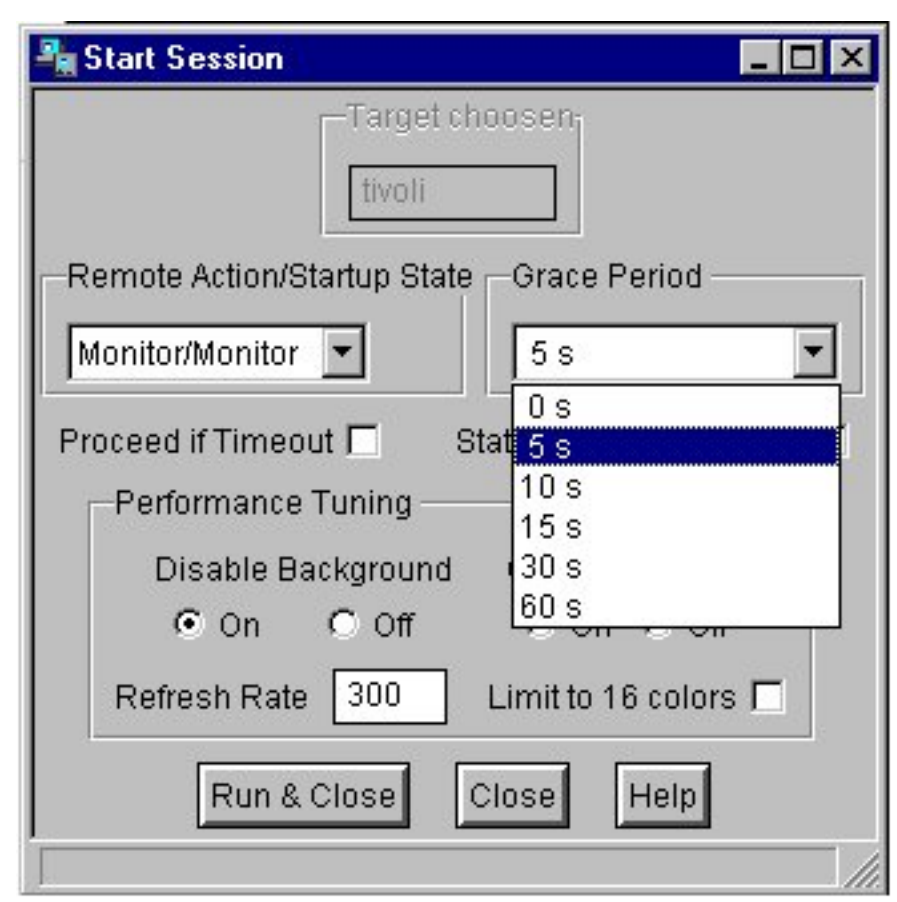

Figura 5.8 - Remote Control time options

Nas primeiras experiências com o Remote Control não obtivemos êxito. Muitas tentativas foram realizadas e muitos erros aconteciam, principalmente erros em arquivos binários na máquina cliente. Tentou-se muitas formas de instalação, formatação de 


\section{Proposta de Arquitetura de Gerência para a RedUnB usando a Plataforma Tivoli TME 10}

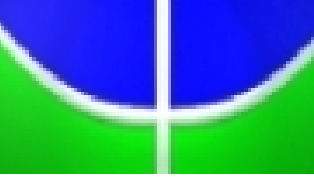

máquinas e procura por vírus, mas os problemas continuaram. Foram realizados testes em várias máquinas, e a máquina em que estava instalada o gerente foi trocada. Reinstalou-se o Tivoli Framework e a disciplina Remote control, mas os erros continuavam. Depois de muitas tentativas, descobriu-se que o erro estava na forma de instalação. A maneira correta de se instalar o software e seus agentes está descrita no item 5.3.1 à frente.

Na aplicação do Remote Control foi realizado a experiência com o SNIFER também, a fim de descobrir quais protocolos eram usados na mesma. Descobrimos que esta aplicação usa o protocolo TCP, como já era esperado para estabelecer uma conexão entre o gerente e o cliente, e, estabelecida esta conexão a aplicação usa o protocolo RPC, que é apresentado na seção 3.10, para executar o Remote Control (ver figura 5.9).

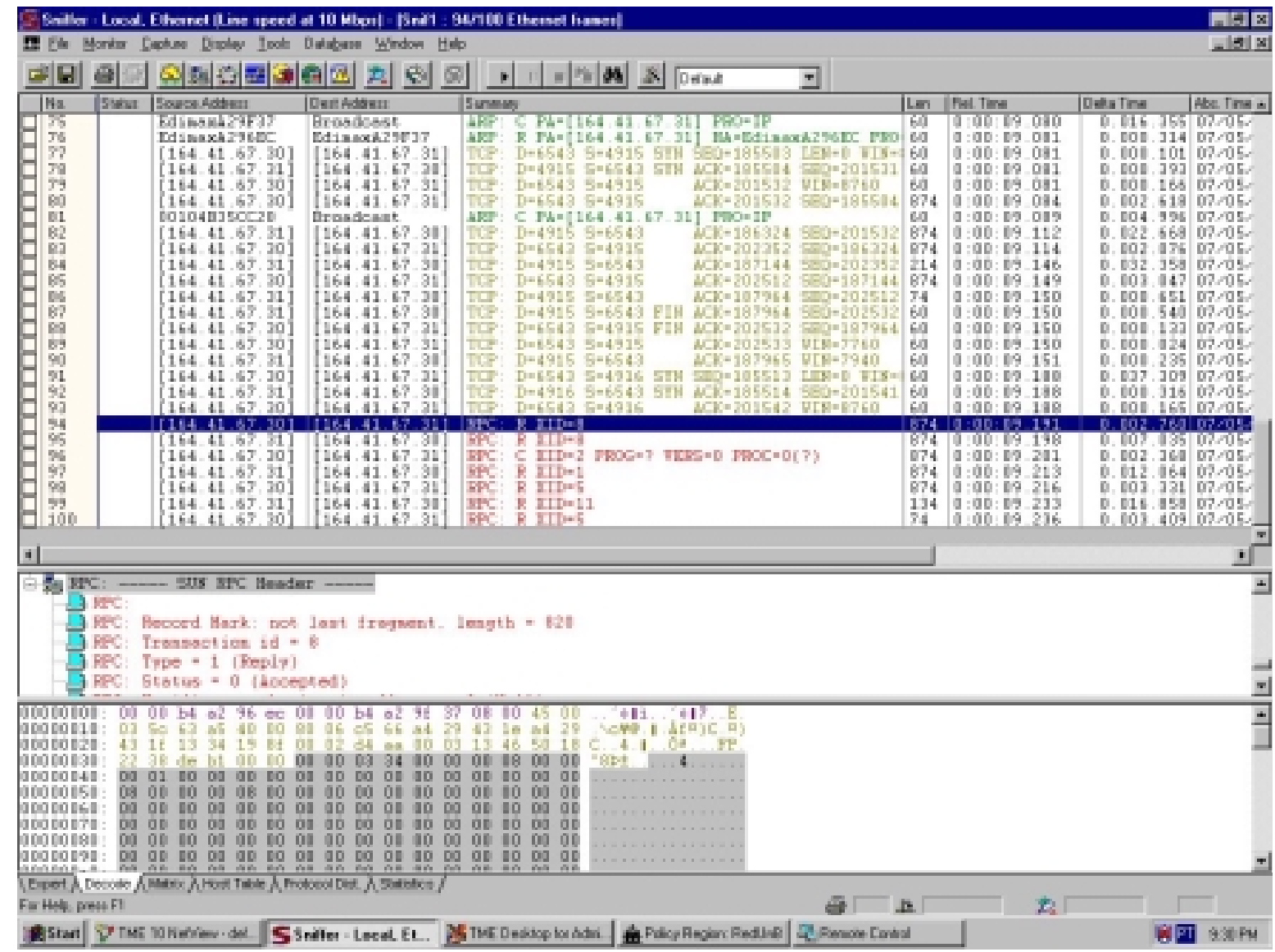

Figura 5.9 - Descoberta de qual protocolo é usado na aplicação Remote Control 


\section{Proposta de Arquitetura de Gerência para a RedUnB usando a Plataforma Tivoli TME 10}

O experimento Remote Control, depois da resolução dos problemas mencionados anteriormente, funcionou em três diferentes máquinas, com diferentes configurações e diferentes sistemas operacionais, provando que está aplicação está pronta para ser colocada em prática em uma rede maior. Demonstrações foram realizadas também com esta aplicação.

\subsection{1 - Resolução de Problemas do Remote Control}

Para que a instalação e o funcionamento da aplicação Remote Control funcione perfeitamente, alguns passos têm que ser seguidos, conforme descritos abaixo:

- Instale no cliente o agente do Remote control que se encontra no CD TME 3.6 Products no diretório especificado abaixo:

\section{RC36/LCF4WIN/FLOPPY/ENGLISH/WINNT40/DISK1/SETUP.EXE}

- Instale no cliente o agente Tivoli, que se encontra no CD TME 10 Framework no diretório especificado abaixo:

PC/TCPAGENT/DISK1/SETUP.EXE

- Rode no cliente os arquivos .BAT que estão no CD TME Products no diretório especificado abaixo:

\section{RC36/SDPACK/WINNT/CTL OU RC36/SDPACK/WINNT/TGT}

Entre no Tivoli Framework instalado na estação de gerência. Clique em Install Products, configure o path para o diretório RC36 do CD TME Products, e instale os agentes do Remote Control pelo Tivoli Framework da estação de gerência isto instalara os arquivos binários necessário para que a aplicação Remote Control funcione.

\section{4 - Sniffer}

Um sniffer é um software que recolhe informações que trafegam por uma rede. Esta rede pode estar rodando qualquer protocolo: Ethernet, TCP/IP, IPX, ou outros (ou qualquer combinação destes). O propósito de um sniffer é colocar a interface de rede neste caso em modo promíscuo e, fazendo isso, capturar todo tráfego da rede que passa pelo barramento em que o mesmo está conectado. 


\section{Proposta de Arquitetura de Gerência para a RedUnB usando a Plataforma Tivoli TME 10}

O software Sniffer Pro version 2.50 .07 foi instalado na máquina gerente, afim de se obter um conhecimento maior da rede que se deseja gerenciar, bem como conhecer melhor os softwares que executam esta gerência. Com a coleta de pacotes que trafegam naquele barramento especifico, conseguimos descobrir quais protocolos eram usados em cada aplicação, e se essas aplicações aumentavam muito o trafego de pacotes pela rede. O sniffer também proporciona que seja visto, com quais máquinas o gerente está se comunicando, observando assim o polling realizado pela máquina gerente na rede. Este software também pode, e é usado, na segurança, tendo em vista que pacotes não podem chegar, ou sair da estação gerente sem serem capturados pelo sniffer, logicamente quando o mesmo está ativo.

Esta versão de sniffer usada nesta experiência é capaz de capturar e armazenar os 100 últimos pacotes transmitidos na rede, o que para descobrir protocolos, ou descobrir com quem a máquina gerente está se comunicando, é o necessário. Porém para que se crie uma gerência segura e mais completa em todos os sentidos, seria necessário a aquisição de um software de sniffer mais completo, que armazenasse mais pacotes e com mais recursos que o atualmente utilizado.

Como já foi mencionado em outras experiências descritas anteriormente, esta experiência nos ajudou muito no aprendizado de outros softwares, e mesmo em uma melhora significativa no nível de gerência que gostaríamos de ter em nossa rede. O sniffer se mostrou uma ferramenta indispensável a uma gerência de qualidade. 


\section{6 - Proposta de gerência}

De acordo com os estudos realizados pelos integrantes deste grupo com a orientação dos professores e ao analisarmos a rede lógica apresentada pelo software Tivoli NetView através da sua interface gráfica e realizado a operação de Discovery da rede, chegou-se a seguinte proposta para implementação de uma rede gerenciada de forma eficiente e descentralizada, utilizando para isso, o software Tivoli TME.

Pode-se ter uma visão geral da proposta observando-se a figura 6.1 .

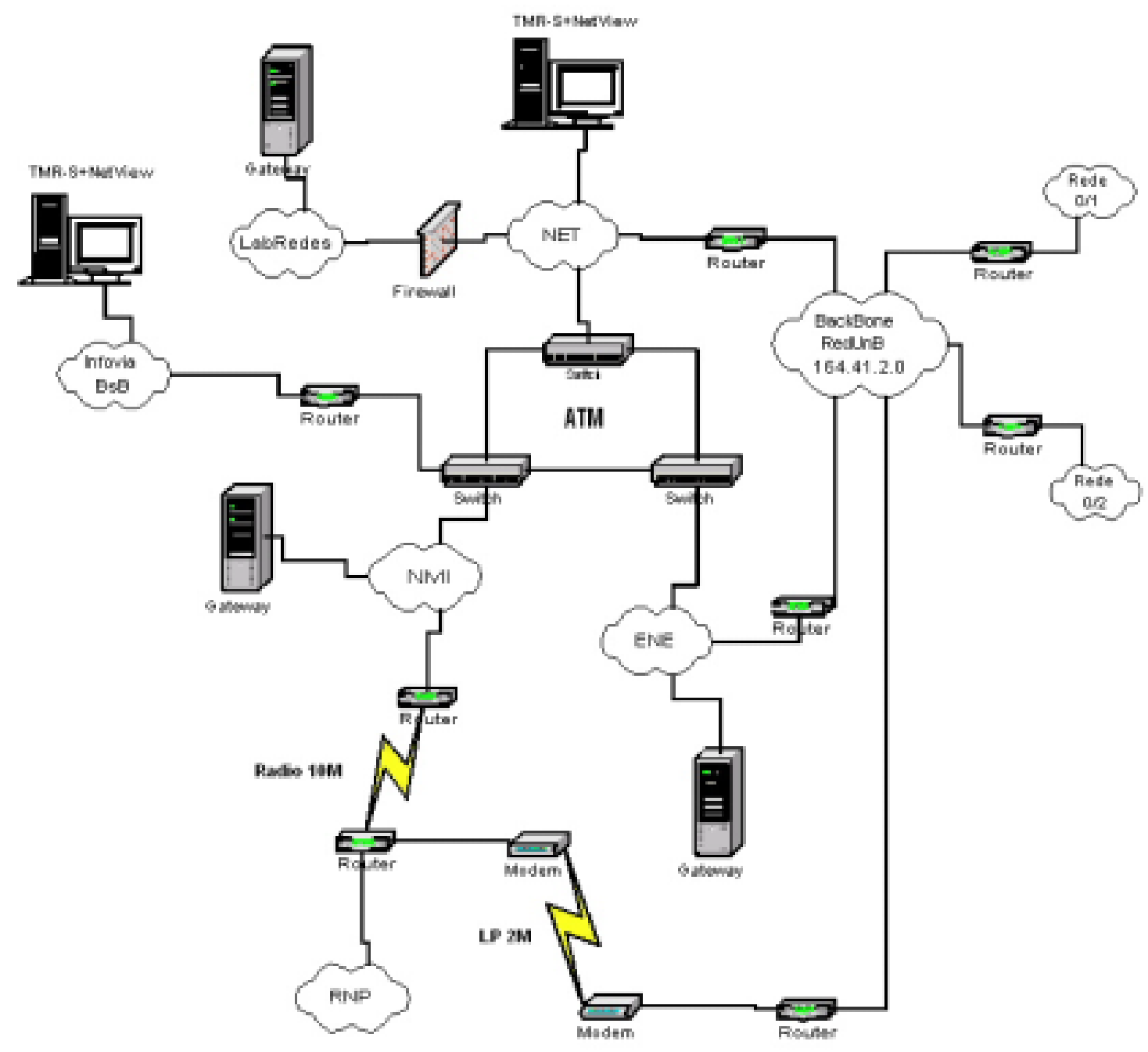

Figura 6.1 - Proposta de Gerência 


\section{Proposta de Arquitetura de Gerência para a RedUnB usando a Plataforma Tivoli TME 10}

A estação central de gerência TMR-S (Tivoli Management Regions - Server) está localizada no Departamento de Engenharia Elétrica no Laboratório de Redes, nesta máquina estão instalados os softwares de gerência da IBM, a base destes programas é o Tivoli FrameWork, sobre o qual está instalado o software Tivoli e seus pacotes em especial o NetView que realiza o mapeamento da rede de forma gráfica.

Foi decidido manter o TMR-S gerenciando o backbone da RedUnB até as bordas, ou seja, até os roteadores que fazem fronteira com as redes locais dos departamentos localizados no ICC na UnB, além do backbone ATM que é constituído de três switches ATM que formam um anel, como pode ser visualizado na figura acima apresentada, também localizado no Laboratório de Redes.

Optou-se por instalar um Gateway Tivoli no laboratório ao lado do que está instalado o TMR-S, isso foi feito para que se testasse a eficiência do Tivoli gerenciando uma rede localizada atrás de um Firewall. Também se pretendia realizar o experimento da distribuição de software de forma remota para as máquinas localizadas naquele laboratório.

Outro local onde deverá ser instalado outro Gateway é no backbone do Departamento de Engenharia Elétrica - ENE para descentralizar a gerência evitando que o TMR-S fique sobrecarregado com, por exemplo, o tráfego de pacotes de polling realizado constantemente pelo NetView. Além de se tratar de uma rede externa ao ambiente de trabalho em que o TMR-S está inserido.

Finalmente propõe-se a instalação de um Gateway no ambiente do NMI por também ser um ambiente externo ao Laboratório de Redes e por possuir características especiais como um link de rádio direto com a RNP.

As instalações dos Gateways não foram realizadas pois era necessária uma licença de instalação de cliente Tivoli que não estava disponível no período da realização deste projeto.

Esta proposta de gerência distribuída foi elaborada desta forma para que fosse possível obter informações de maneira segura de várias redes com as mais diversas configurações e ambientes, os gateways proporcionariam uma visão descentralizada da rede como um todo, facilitando a localização de possíveis problemas, além de 


\section{Proposta de Arquitetura de Gerência para a RedUnB usando a Plataforma Tivoli TME 10}

minimizar o tráfego de informações entre os endpoints e o TMR-S ampliando significativamente o número de máquinas a serem gerenciadas.

Esta decisão foi tomada tendo por base as informações contidas no Manual do TME 10 Framework (TME 10 Framework Planning and Installation Guide), tais informações estão apresentadas a seguir.

\section{1 - Sugestões de Pacotes do Tivoli TME 10 a Serem Adquiridos}

Para encerrar esta proposta de gerência serão apresentadas sugestões de Pacotes do Tivoli TME 10 a serem adquiridos e que, segundo a concepção deste grupo juntamente com a orientação dos professores, seriam de grande utilidade para que a gerência da RedUnB possa ser realizada de maneira eficiente.

A plataforma Tivoli apresenta vários pacotes, cada um com várias disciplinas que realizam diferentes funções. Os pacotes apresentados pelo Tivoli em seu site serão apresentados abaixo. Os pacotes apresentados são:

- Asset Management

- Availability Management

- Change Management

- Network Management

- Operations Management

- Security Management

- Service Management

- Storage Management

Availability Management:

Este pacote inclui as seguintes disciplinas:

- Tivoli Application Performance Management:

- Tivoli Distributed Monitoring:

- Tivoli Global Enterprise Manager 
- Tivoli Management Framework

- Tivoli Netview Performance Monitor

- Tivoli Remote Control

- Wired for Management

\section{Change Management:}

Este pacote inclui as seguintes disciplinas:

- Tivoli Asset Management

- Tivoli Decision Support

- Tivoli Inventory

- Tivoli Management Framework

- Tivoli Manager for Network Hardware

- Tivoli NetView Distribution Manager

- Tivoli NetView File Transfer Program

- Tivoli Problem Management

- Tivoli Remote Control

- Tivoli Security Management

- Tivoli Service Desk

- Tivoli Software Distribution

- Wired for Management

Network Management:

Este pacote inclui as seguintes disciplinas:

- Distributed Solutions-TCP/IP Network Management

- Tivoli NetView 6.0

- Tivoli Manager for Network Hardware

- Tivoli Comprehensive Network Address Translator

- Tivoli Network Connectivity and Performance Manager

- Tivoli NetView Performance Monitor for TCP/IP 


\section{Proposta de Arquitetura de Gerência para a RedUnB usando a Plataforma Tivoli TME 10}

\section{7 - Conclusões}

Essa proposta de gerência contribuiu para que futuras melhoras nos níveis de serviço de rede da RedUnB sejam realizados, servindo de base para que uma posterior política de gerência seja implantado na mesma, de forma que o desempenho, a eficiência, a segurança e a confiabilidade da rede desta instituição tão conceituada dê aos alunos, professores e outros usuários desta rede condições de trabalho e pesquisa melhores.

Durante este projeto alguns problemas surgiram e a maioria deles foi superada com sucesso, não foi possível realizar todos os experimentos que haviam sido planejados no princípio deste projeto, tais como o Software Distribution, e configuração de Endpoints e Gateways, tais problemas surgiram principalmente pela falta de licenças de instalação dos produtos que realizariam tais operações.

O grupo considera que o trabalho realizado foi de grande valia pois espera-se que ele vá servir de base à trabalhos futuros que visem a implantação de uma política de gerência envolvendo toda a RedUnB.

Tendo realizado os testes em ambiente semelhante ao da RedUnB, apenas em uma escala menor, pôde-se perceber a força do software utilizado e sua versatilidade ao gerenciar um ambiente multiplataforma; além dos estudos realizados visando ter um maior conhecimento das necessidades de gerência da RedUnB e as soluções que o Tivoli oferece. 


\section{Bibliografia}

[1] Stallings, Willian. "SNMP, SNMPv2, SNMPv3 e RMON1 e 2" terceira edição. Publicado por Addison Wesley, Dezembro, 1998.

[2] Douglas E. Comer. "Internetworking with TCP/IP - Vol I Principles, Protocols and Arquiteture" terceira edição. Publicado por Prentice Hall, 1995.

[3] Site da Tivoli IBM - http://www.tivoli.com/products/solutions

[4] Repositório de Documentos Técnicos do Grupo de Redes - UFRGS.

[5] Sites: http://www.di.ufpe.br/ flash/ais98/gerrede/gerrede.html http://www.penta.ufrgs.br/gr952/trab1/2mibII.html http://penta.ufrgs.br/homegere.htm http://penta.ufrgs.br/gr952/trab1/rmon.html http://penta.ufrgs.br/home_red.htm http://penta.ufrgs.br/homeosi.html http://www.rnp.br/newsgen/ascii/n3.txt http://www.rnp.br/newsgen/9712/9712index.html 